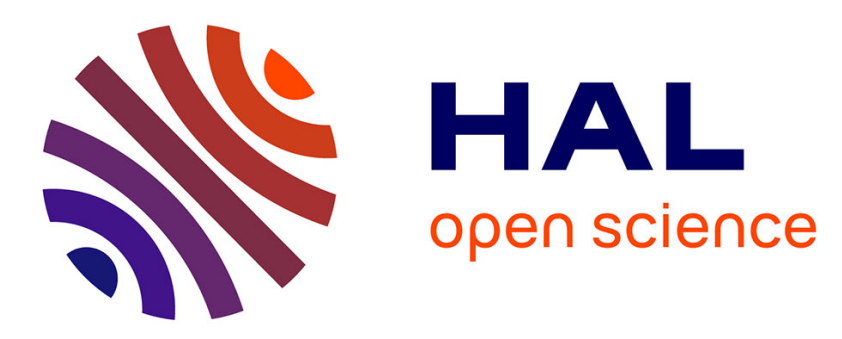

\title{
An overview of siderophore biosynthesis among fluorescent Pseudomonads and new insights into their complex cellular organization
}

\author{
Isabelle Schalk, Coraline Rigouin, Julien Godet
}

\section{To cite this version:}

Isabelle Schalk, Coraline Rigouin, Julien Godet. An overview of siderophore biosynthesis among fluorescent Pseudomonads and new insights into their complex cellular organization. Environmental Microbiology, 2020, Metal(loid) Microbiology, 22 (4), pp.1447-1466. 10.1111/1462-2920.14937 . hal03017527

\author{
HAL Id: hal-03017527 \\ https://hal.science/hal-03017527
}

Submitted on 20 Nov 2020

HAL is a multi-disciplinary open access archive for the deposit and dissemination of scientific research documents, whether they are published or not. The documents may come from teaching and research institutions in France or abroad, or from public or private research centers.
L'archive ouverte pluridisciplinaire $\mathbf{H A L}$, est destinée au dépôt et à la diffusion de documents scientifiques de niveau recherche, publiés ou non, émanant des établissements d'enseignement et de recherche français ou étrangers, des laboratoires publics ou privés. 


\section{An overview of siderophore biosynthesis among fluorescent Pseudomonads and new insights into their complex cellular organization}

\author{
Isabelle J. Schalk (1), ${ }^{1,2}$ Coraline Rigouin ${ }^{1,2 *}$ and \\ Julien Godet ${ }^{3}$ \\ ${ }^{1}$ CNRS, UMR7242, ESBS, Illkirch, Strasbourg, France. \\ ${ }^{2}$ Université de Strasbourg, UMR7242, ESBS, Illkirch, \\ Strasbourg, France. \\ ${ }^{3}$ Université de Strasbourg, Laboratoire de Biolmagerie \\ et Pathologies, UMR CNRS, 7021, Illkirch, France.
}

\section{Summary}

Siderophores are iron-chelating molecules produced by bacteria to access iron, a key nutrient. These compounds have highly diverse chemical structures, with various chelating groups. They are released by bacteria into their environment to scavenge iron and bring it back into the cells. The biosynthesis of siderophores requires complex enzymatic processes and expression of the enzymes involved is very finely regulated by iron availability and diverse transcriptional regulators. Recent data have also highlighted the organization of the enzymes involved in siderophore biosynthesis into siderosomes, multi-enzymatic complexes involved in siderophore synthesis. An understanding of siderophore biosynthesis is of great importance, as these compounds have many potential biotechnological applications because of their metal-chelating properties and their key role in bacterial growth and virulence. This review focuses on the biosynthesis of siderophores produced by fluorescent Pseudomonads, bacteria capable of colonizing a large variety of ecological niches. They are characterized by the production of chromopeptide siderophores, called pyoverdines, which give the typical green colour characteristic of fluorescent pseudomonad cultures. Secondary siderophores are also produced by these strains and can have highly diverse structures (such as pyochelins, pseudomonine, yersiniabactin, corrugatin, achromobactin and quinolobactin).

Received 5 December, 2019; revised 25 January, 2020; accepted 28 January, 2020. *For correspondence.E-mail schalk@ unistra.fr.

\section{Introduction}

Siderophores are a major family of iron-chelating agents that play a key role in bacterial iron homeostasis. They generally have a molecular weight between 200 and $2000 \mathrm{Da}$ and are characterized by a very strong affinity for ferric iron $\left(\mathrm{Fe}^{3+}\right)$ (Boukhalfa and Crumbliss, 2002). They are produced and secreted by bacteria under ironrestricted conditions to scavenge iron from their environment. In parallel, bacteria express transporters at their cell surface that are able to capture back these chelators once they have chelated ferric iron (Schalk et al., 2012).

Fluorescent pseudomonads produce the fluorescent pyoverdines as their major siderophores (Cornelis and Matthijs, 2002; Meyer et al., 2002). These chelators are produced by the bacteria to access iron and also play an important role in the virulence of Pseudomonad pathogens and, in the case of $P$. aeruginosa, have been shown to be necessary for the establishment of mature biofilms (Meyer et al., 1996; Handfield et al., 2000; Mirleau et al., 2000; Banin et al., 2005; Yang et al., 2009; Taguchi et al., 2010). In addition, diverse secondary siderophores with a lower affinity for $\mathrm{Fe}^{3+}$ are also produced by Pseudomonads, such as pyochelin (PCH), pseudomonin, corrugatins and ornicorrugatins, yersiniabactin and thioquinolobactin (Cornelis, 2010).

This review will focus on the biosynthesis of the siderophores produced by fluorescent Pseudomonads, the enzymatic biochemistry involved, the cellular organization of the biosynthetic machinery, and how siderophore synthesis is regulated. Pseudomonas aeruginosa is the archetype among fluorescent Pseudomonads and most of the data found in the literature and presented here will concern this pathogen; however, parallels will be made with siderophore biosynthesis among other fluorescent Pseudomonads, when possible. Pseudomonas aeruginosa strains produce four distinct pyoverdines, called PVDI, PVDII, PVDIII and PVDIV, and PCH as a secondary siderophore (Schalk and Guillon, 2013; Gasser et al., 2015; Ringel and Brüser, 2018; Ronnebaum and Lamb, 2018). Many detailed reviews have already been published on PVDI and PCH biosynthesis (Visca et al., 2007; Schalk and Guillon, 2013; Gasser et al., 2015; Ringel and Brüser, 
2018; Ronnebaum and Lamb, 2018). Thus, we will provide a general description of their biosynthesis and highlight recent and original data concerning the cellular organization of the siderophore biosynthetic machinery. Indeed, high-resolution fluorescence microscopy and approaches such as fluorescence recovery after photobleaching (FRAP) or single-molecule tracking with photoactivated localization microscopy (sptPALM) have provided new insights into the cellular distribution of the biosynthetic enzymes within the bacteria, their dynamics in the bacterial cytoplasm and the possible protein interactions involved (Guillon et al., 2012; Guillon et al., 2013; Imperi and Visca, 2013; Gasser et al., 2015; Gasser et al., 2020). These recent data provide a new vision of siderophore biosynthesis.

\section{Siderophores produced by Pseudomonas strains}

\section{Pyoverdines}

All fluorescent Pseudomonads produce pyoverdines and almost 100 distinct pyoverdines, produced by various strains and species of fluorescent Pseudomonas, have been identified to date (Demange et al., 1990; Budzikiewicz, 1997; Fuchs and Budzikiewicz, 2001; Budzikiewicz, 2004; Budzikiewicz et al., 2007). These siderophores all have the same structural organization, consisting of three components (Fig. 1A): (i) a dihydroquinoline-type chromophore, (ii) a strain-specific peptide comprised of six to 14 amino acids, and (iii) a side-chain bound to the nitrogen atom at position $\mathrm{C}-3$ of the chromophore. The chromophore is (1S)-5-amino-2,3-dihydro-8,9-dihydroxy-1H-pyrimido-[1,2-a]quinolone1-carboxylic acid and is exactly the same for all pyoverdines, giving specific spectral characteristics to these compounds, consisting of an absorbance at $400 \mathrm{~nm}$ (at neutral $\mathrm{pH}$ ) and an emission of fluorescence at $447 \mathrm{~nm}$ when in the apo forms (the ferric form being non-fluorescent) (Albrecht-Gary et al., 1994; Folschweiller et al., 2002; Budzikiewicz et al., 2007). The side chain bound to the chromophore is, in most cases, a succinamide, succinate or $\alpha$-ketoglutaric acid or sometimes also malamide, malic acid or succinic acid.

The sequence and length of the peptide moiety differ between pyoverdines and may contain unusual amino acids, such as D-isomers and amino acids that are not usually found in proteins (such as $N^{5}$ hydroxycycloornithine or L-2,4-diaminobutyrate) (Budzikiewicz, 1997; Fuchs and Budzikiewicz, 2001; Meyer et al., 2002). This peptide moiety can also be cyclic in some pyoverdines. Each pyoverdine is characterized by its sequence, which gives each Pseudomonas strain the ability to access iron using only the pyoverdine produced by itself. This is due to the fact that
Pseudomonas strains produce a specific pyoverdine and express a corresponding specific transporter at the outer membrane that is able to recognize and capture back only the ferric form of the produced pyoverdine or one that is structurally related (with a similar peptide sequence) (Greenwald et al., 2009; Schalk et al., 2012). The peptide moiety plays a key role in such transporter recognition, as shown by the $\mathrm{x}$-ray structures of a pyoverdine transporter in complex with several different ferric-pyoverdine complexes (Greenwald et al., 2009). As already mentioned in the Introduction, four distinct pyoverdines are produced by $P$. aeruginosa strains-PVDI, PVDII, PVDIII and PVDIV. Each is characterized by a different peptide chain (Fig. 1A) (Meyer et al., 1997; Ruangviriyachai et al., 2001) and each has a corresponding outer membrane transporter FpvAl, FpvAll, FpvAll and FpvAIV. Overall, almost 100 pyoverdines produced by all fluorescent Pseudomonads are divided into four groups or families based on the structural features of the peptide chain [for more details see (Fuchs et al., 2001)].

Pyoverdines chelate iron with a 1:1 stoichiometry and an affinity of $10^{32} \mathrm{M}^{-1}$ for ferric iron has been determined for PVDI produced by $P$. aeruginosa PAO1 (AlbrechtGary et al., 1994). The chelating groups always involve the catechol and two bidentate ligands from the peptide moiety (Fig. 1A). As for most siderophores, pyoverdines are able to chelate many metals other than iron (Braud et al., 2009b; Hannauer et al., 2012a) and stability constants have been determined for PVD- $\mathrm{Ni}^{2+}$ $\left(\mathrm{Ka}=10^{10.9} \mathrm{M}^{-1}\right), \mathrm{PVD}-\mathrm{Cd}^{2+}\left(\mathrm{Ka}=10^{8.2} \mathrm{M}^{-1}\right)$ and PVD$\mathrm{Cu}^{2+}\left(\mathrm{Ka}=10^{20.1} \mathrm{M}^{-1}\right)$ (Ferret et al., 2014).

\section{Other siderophores produced by Pseudomonads}

Almost all fluorescent Pseudomonads produce another siderophore in addition to pyoverdine, often called the secondary siderophore because of a lower affinity for ferric iron relative to that of pyoverdine (Cornelis and Matthijs, 2002; Mossialos and Amoutzias, 2007; Matthijs et al., 2008; Matthijs et al., 2009). Such secondary siderophores can have diverse chemical structures (Fig. 1B). In addition to pyoverdines, $P$. aeruginosa strains produce $\mathrm{PCH}$. PCH chelates ferric iron with a 2:1 stoichiometry and an affinity of $10^{18} \mathrm{M}^{-2}$ (Cox et al., 1981; Tseng et al., 2006; Brandel et al., 2012). Pseudomonas fluorescens produces enantio-pyochelin (E-PCH)-the optical antipode of $\mathrm{PCH}-($ Youard et al., 2007; Hoegy et al., 2009), $P$. syringae DC3000 yersiniabactin (also produced by Yersinia) (Jones et al., 2007; Petermann et al., 2008) and $P$. syringae B728a achromobactin (also produced by Erwinia chrysanthemi) (Franza et al., 2005; Berti and Thomas, 2009). This list shows that secondary siderophores are not always specific to Pseudomonads but are sometimes also produced by other bacterial species. Pyridine-2,6-bis(thiocarboxylate) (PDTC) has been 
A

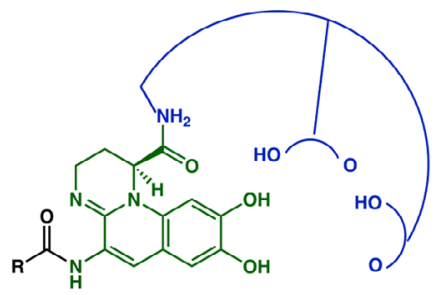

succinamide: $\mathrm{R}=\mathrm{CH}_{2} \mathrm{CH}_{2} \mathrm{CONH}_{2}$ succinic: $\mathrm{R}=\mathrm{CH}_{2} \mathrm{CH}_{2} \mathrm{COOH}$ $\alpha$-cetoglutaric $=\mathrm{R}=\mathrm{CO}-\mathrm{CH}_{2} \mathrm{CH}_{2} \mathrm{COOH}$

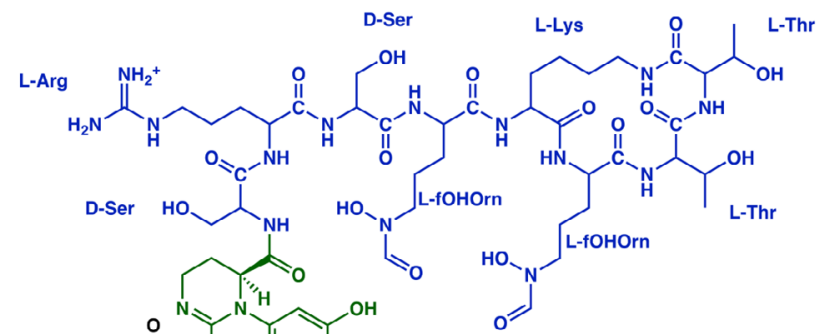

Pyoverdine (PVDI)

Sequence of the peptide chain for the 4 pyoverdines produced by $P$. aeruginosa strains:

PVDI : D-Ser-L-Arg-D-Ser-L-fOHOrn-[L-Lys-L-fOHOrn-L-Thr-L-Thr]

PVDII : D-Ser-L-fOHOrn-L-Orn-Gly-D-Thr-L-Ser-L-cOHOrn

PVDIII : D-Ser-Dab-L-fOHOrn-L-GIn-D-GIn-L-fOHOrn-Gly

PVDIV : D-Ser-Dab-L-fOHOrn-L-Gln-L-fOHOrn-Gly

B<smiles>CC1[C@H](C(=O)O)SC[C@H]1C1CSC(c2ccccc2O)=N1</smiles>

Pyochelin $P$. aeruginosa<smiles>CC1ON(CCc2c[nH]cn2)C(=O)C1NC(=O)c1ccccc1O</smiles>

Pseudomonine $P$. fluorescens $P$. entomophilia

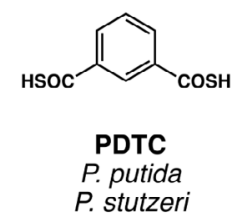<smiles>CC1[C@H](C(=O)O)CS[C@H]1C1CSC(c2ccccc2O)=N1</smiles>

Enantio-pyochelin $P$. fluorescens<smiles>O=C(CC(O)(CC(=O)OCCN1C(=O)CCC1(O)C(=O)O)C(=O)O)NCC[C@H](C(=O)O)N1C(=O)CCC1(O)C(=O)O</smiles>

Achromobactin $P$. syringae<smiles>CC(C)(C1=N[C@@](C)(C(=O)O)CS1)[C@@H](O)[C@@H]1CS[C@H]([C@H]2CSC(c3ccccc3O)=N2)N1</smiles>

Yersiniabactin $P$. syringae

Fig. 1. A. General structure of pyoverdines and the structure of PVDI, the pyoverdine produced by $P$. aeruginosa PAO1. The chromophore is in green, the side chain in black and the peptide moiety in blue. The sequences of the peptide moiety of the four pyoverdines produced by $P$. aeruginosa strains are also shown.

B. Structures of the secondary siderophores produced by fluorescent Pseudomonads. Pyochelin (PCH) is produced by Pseudomonas aeruginosa, Enantio-pyochelin (E-PCH) by Pseudomonas fluorescens (Youard et al., 2007; Hoegy et al., 2009), Yersiniabactin and Achromobactin by Pseudomonas syringae (Jones et al., 2007; Petermann et al., 2008), Pseudomonine by Pseudomonas fluorescens and Pseudomonas entomophila (Mercado-Blanco et al., 2001; Matthijs et al., 2009), Quinolobactin and Thio-quinolobactin by Pseudomonas fluorescence ATCC17400 (Matthijs et al., 2004; Matthijs et al., 2007), PDTC (Pyridine-2,6-bis(thiocarboxylate)) by Pseudomonas stutzeri (Lee et al., 1999) and Pseudomonas putida (Ockels et al., 1978) and Corrugatin by Pseudomonas acorrugata (Matthijs et al., 2008).

shown to be produced by $P$. stutzeri (Lee et al., 1999) and $P$. putida (Ockels et al., 1978) and is capable of transporting iron (Lewis et al., 2004). The role of secondary siderophores is not clear, but they are often produced in lower iron-restricted conditions than pyoverdines (Cunrath et al., 2016). Like pyoverdines, secondary siderophores are able to chelate metals other than iron. $\mathrm{PCH}$ has been shown to form complexes with many metals 
(Baysse et al., 2000; Braud et al., 2009a) and the stability constant has been determined for $\mathrm{Zn}^{2+}\left(\mathrm{Ka}=10^{26.0} \mathrm{M}^{-2}\right)$ and $\mathrm{Cu}^{2+}\left(\mathrm{Ka}=10^{25.0} \mathrm{M}^{-2}\right)$ (Brandel et al., 2012).

\section{Biosynthesis}

The biosynthetic pathways of PVDI and PCH produced by $P$. aeruginosa PAO1 have been extensively investigated and all steps and enzymes involved have been identified and characterized. An overall description of these two biosynthetic schemes is presented below. As the biosynthesis of other pyoverdines must be very similar to that of PVDI, we also discuss the gene organization of pyoverdine biosynthesis among fluorescent Pseudomonads in general. Much less, and sometimes nothing, is known about the biosynthesis of the other secondary siderophores produced by fluorescent Pseudomonads: hypothetical or incomplete biosynthetic pathways have been proposed for PDTC, quinolobactin, thioquinolobactin and achromobactin (summarized below). The biosynthesis of yersiniabactin has been described in detail in $Y$. pestis (Ahmadi et al., 2015) but not in $P$. syringae, but probably very similar enzymes and biological mechanisms are involved (Ahmadi et al., 2015).

\section{Pyoverdine biosynthesis}

Knowledge of the various steps of PVDI biosynthesis, the pyoverdine produced by $P$. aeruginosa PAO1, is very complete and precise. PVDI synthesis starts in the bacterial cytoplasm, with the assembly of an 11-amino-acid peptide with an unformed chromophore and a myristic or myristoleic acid chain at its $\mathrm{N}$-terminal end (Hannauer et al., 2012b). This cytoplasmic peptide undergoes maturation in the periplasm to yield PVDI (Yeterian et al., 2010; Hannauer et al., 2012b). Its biosynthesis involves the coordinated action of several enzymes, including four non-ribosomal peptide synthesis (NRPS) enzymes, three enzymes that generate atypical amino acids present in the peptide moiety of the siderophore, and several enzymes involved in the maturation of this siderophore in the bacterial periplasm before secretion.

The PVDI peptide backbone contains two unusual amino acids, L-2,4-diaminobutyrate (L-Dab) and L- $N_{5}$-formyl- $N_{5}$-hydroxyornithine (L-fOHOrn). L-Dab is synthesized by the enzyme $\mathrm{PvdH}$, an aminotransferase that catalyses the formation of L-Dab from L-aspartate $\beta$-semialdehyde (Vandenende et al., 2004) (Fig. 2A). L-fOHOrn is synthesized from L-ornithine by hydroxylation and formylation catalysed by PvdA and PvdF respectively (Visca et al., 1994; McMorran et al., 2001; Ge and Seah, 2006). Other unusual amino acids can be found in pyoverdine sequences of Pseudomonas strains, such as $\beta$-hydroxy aspartic acid, $\beta$-hydroxy histidine, ornithine, cyclo- $\mathrm{N}_{5^{-}}$ hydroxy ornithine, $N_{5}$-acetyl- $N_{5}$-hydroxy ornithine and $N_{5}$ hydroxybutyryl- $N_{5}$-hydroxy ornithine (Cezard and Sonnet, 2014). Some of the enzymes involved in such modifications have been identified. For example, PvdY is the enzyme responsible for the acetylation of hydroxyornithine in the biosynthesis of type II pyoverdine (PVDII) in P. aeruginosa strains (Lamont et al., 2006). PvdY is only present in strains that make PVDII.

The peptide backbone of $P$. aeruginosa PVDI is composed of 11 amino acids, which are assembled by NRPS enzymes (Fig. 2A), multi-modular enzymes that activate amino acids and assemble them into peptide chains. Each module of one NRPS enzyme activates and modifies a specific amino acid for addition to the growing peptide chain that is then elongated with another amino acid activated and modified by an adjacent module. Consequently, the number and order of the NRPS modules directly dictate the linear sequence of the final peptide chain. A typical module contains three domains: an adenylation (A) domain, a condensation (C) domain and a peptidyl-carrier protein (PCP) domain. The A domain recognizes a specific amino acid and activates the acid by an ATP-dependent adenylation. Then, the acid is transferred to a free thiol of a covalently bound phosphopantetheine cofactor of the adjacent PCP domain by thioesterification to form an acyl-S-PCP domain intermediate. Finally, the $C$ domain catalyses the condensation between upstream and downstream PCP-thioesterified substrates, forming the peptide bond between the two amino acids. A more detailed description of the biochemistry of NRPS enzymes is provided in reviews by Hur et al. (2012), Gulick (2017), and Süssmuth and Mainz (2017). The last NRPS of the assembly line usually has a thioesterase domain, adjacent to the terminal PCP domain, which catalyses hydrolysis of the peptide chain from the NPRS, leading to its release (Izoré and Cryle, 2018). The biosynthesis of the PVDI precursor requires four NPRS enzymes: PvdL, Pvdl, PvdJ and PvdD (Fig. 2A). The synthesis starts with PvdL, an NRPS enzyme composed of four modules (Mossialos et al., 2002). The first module of PvdL is unusual and consists of an acyl coenzyme A ligase domain that catalyses the acylation of a myristic acid or a myristoleic acid. It has been suggested that this acylation occurs to maintain the peptide precursor at the membrane and prevent its diffusion during assembly of the peptide (Hannauer et al., 2012b). The second module of PvdL catalyses the activation of L-Glu and its condensation to the myristic acid-coA formed in the first module. The third module binds an LTyr amino residue. An epimerization domain embedded in this module isomerizes the L-Tyr residue to the D-Tyr form. Finally, the fourth module adds the L-Dab amino acid to form the acylated tripeptide L-Glu/D-Tyr/L-Tab. The second NRPS involved, Pvdl, is composed of four 
A

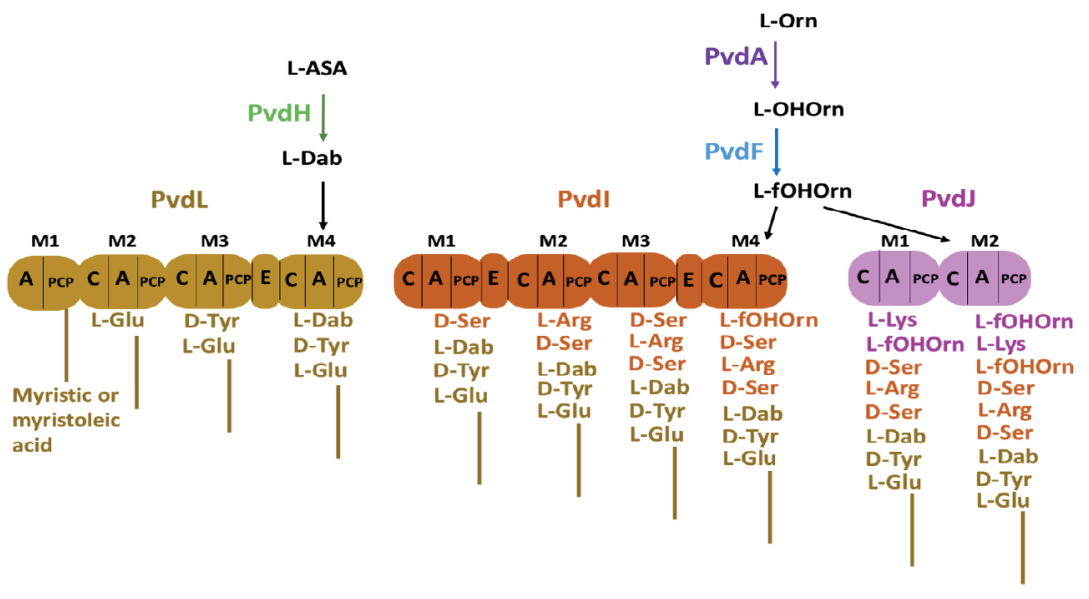

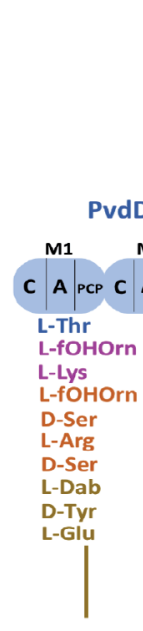

PvdD

12
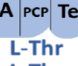

L-Thr

L-fOHOrn

L-Lys

L-fOHOrn

D-Ser

L-Arg

D-Ser

L-Dab

D-Tyr
L-Glu

D-Tyr
L-Glu

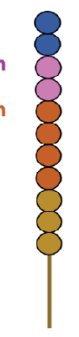

Pyoverdin

precursor

\section{B}

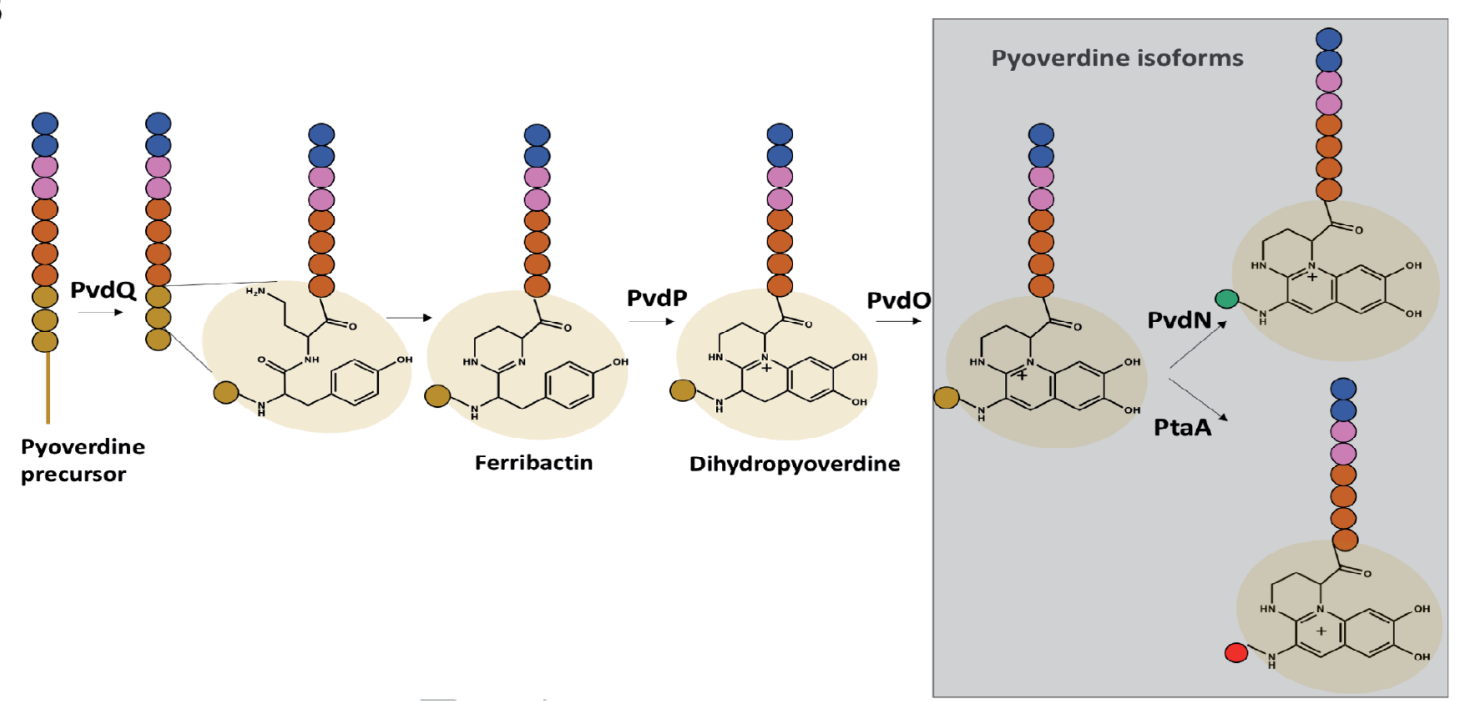

Fig. 2. Biosynthesis pathways of PVDI in $P$. aeruginosa PAO1. A. Synthesis of the pyoverdine precursor in the bacterial cytoplasm. Each of the four NRPS (PvdL, Pvdl, PvdJ and PvdD) involved in the synthesis is divided into modules (M). Each module is composed of a condensation domain $(C)$, an acetylation domain $(A)$ and a peptidyl carrier protein (PCP) domain. PvdL and Pvdl contain epimerization domains (E) and PvdD a thioesterase domain (Te). The amino acids incorporated in the chain are indicated below each module, depicted by the corresponding colour and represented by coloured circles in the final precursor.

B. Maturation of pyoverdine precursor into PVDI isoforms in the bacterial periplasm. After translocation of pyoverdine precursor from the cytoplasm into the periplasm via PvdE, pyoverdine precursor undergoes a maturation process involving five enzymes (PvdQ, PvdP, PvdO, PvdN and $\mathrm{PtaA})$. The green and red circles on pyoverdine isoforms represent succinic acid and $\alpha$-ketoglutaric acid respectively. For more details on PVDI biosynthesis see the text.

modules and adds the amino acids D-Ser, L-Arg, D-Ser and L-hfOrn to the precursor peptide formed by PvdL. Pvdl contains epimerization domains in modules 2 and 4 to generate D-Ser from L-Ser (Lehoux et al., 2000). The two following NRPS enzymes are PvdJ and PvdD, which are bimodular and add L-lys and L-hfOrn and two L-Thr residues respectively (Merriman et al., 1995; Ackerley et al., 2003). The last module of PvdD has a final thioesterase domain that catalyses the hydrolysis of the peptide chain from the NRPS. Two genes, PA2411 and
PA2425 (pvdG), are predicted to encode thioesterase enzymes and are embedded in the PVDI biosynthetic gene cluster, suggesting a role in PVDI biosynthesis. Whether these thioesterases have overlapping functions, act in trans to release the in-forming peptide, or have another function in PVDI biosynthesis is still not clear. Of note, genetic inactivation of PvdG blocks the synthesis of PVDI (Lamont and Martin, 2003). The last enzyme supposedly involved in PVDI synthesis is MbtH. MbtH-like proteins are small auxiliary proteins that interact with the 
A domain to enhance its activity (Felnagle et al., 2010; Boll et al., 2011). The crystal structure of $P$. aeruginosa MbtH has been solved (Drake et al., 2007). Although direct involvement of MbtH in NRPS activity has not been demonstrated, biochemical studies have provided evidence for a role in the production and secretion of PVDI (Drake et al., 2007).

Once assembled, the acetylated precursor peptide is transported to the periplasm by the ATP-binding-cassette (ABC) inner membrane transporter, PvdE. The involvement of PvdE in periplasmic transport was unravelled by the study of a pvdE mutant that led to undetectable PVDI-related fluorescence in cultures of $P$. aeruginosa cells (Yeterian et al., 2010). Consequently, it was concluded that PvdE exports the non-fluorescent PVDI precursor from the cytosol to the periplasm but is not involved in its extracellular secretion (Yeterian et al., 2010). Once in the periplasm, the PVDI precursor is subjected to modifications that ultimately lead to the final siderophore (Fig. 2B). The first modification is deacetylation of the precursor, performed by the enzyme PvdQ and leading to the removal of the myristic or myristoleic acid moiety from the peptide and formation of a pyoverdine precursor, called ferribactin (Drake and Gulick, 2011; Hannauer et al., 2012b). This precursor then enters an oxidative cyclization cascade that results in chromophore cyclisation from the L-Dab and D-Tyr residues, the second and third residues of the PVDI precursor (Dorrestein et al., 2003; Dorrestein and Begley, 2005), involving the copper-dependent tyrosinase PvdP (Nadal-Jimenez et al., 2014; Poppe et al., 2018). This enzyme catalyses the conversion of ferribactin into dihydropyoverdine in three steps: (i) hydroxylation of the D-tyrosine moiety of the tetrahydropyrimidine ring, resulting in a catechol functionality, (ii) formation of a third ring in the chromophore, and (iii) restoration of the catechol functionality (Nadal-Jimenez et al., 2014; Poppe et al., 2018). The final oxidation of dihydropyoverdine into PVDI has recently been assigned to PvdO (Yuan et al., 2017; Ringel et al., 2018). Ringel et al. (2018) showed that a mutant strain of $P$. fluorescens A506 lacking PvdO only produces the dihydropyoverdine form of PVDI. The authors raised the possibility that PvdO must be associated with another enzyme or a specific cofactor to be active, as the enzyme was inactive in vitro.

The first residue of the pyoverdine peptide backbones among fluorescent Pseudomonads is always a glutamic acid (Hohlneicher et al., 2001). This L-Glu residue, bound at position $\mathrm{C} 3$ of the chromophore, undergoes modifications that allow its conversion into a range of variants, including succinamide, succinic acid, $\alpha$-ketoglutaric acid, malamide and malic acid residues (Budzikiewicz, 2004). These structural variations do not have a direct impact on pyoverdine function but rather on the adaptation to environmental conditions. The two enzymes involved in these modifications have recently been identified and their function assigned. PvdN is an enzyme that contains a pyridoxal phosphate cofactor as a prosthetic group and requires cytoplasmic cofactor assembly for folding (Drake and Gulick, 2016). Ringel et al. showed by mass spectrometry that the only pyoverdine produced by a $p v d N$ mutant is the $\alpha$-ketoglutarate form, indicating that transformation to the succinamide derivatives does not occur and must be carried out by PvdN (Ringel et al., 2018; Ringel and Brüser, 2018). PtaA (PflA506_4424) is also a pyridoxal phosphate-dependent transaminase and requires cytoplasmic cofactor assembly for folding and transport to the periplasm (Ringel et al., 2017). As for PvdN, PtaA is not essential for pyoverdine production or function. However, a $P$. fluorescens A506 mutant deleted for ptaA was unable to produce the $\alpha$-ketoglutaric acid variant, suggesting that this enzyme is responsible for the alternative modification of the LGlu side chain (Ringel et al., 2017). The $\Delta p t a A / \Delta p v d N$ double-deletion strain produced neither the succinamide variant (and further derivatives) nor the $\alpha$-ketoglutaric-acid variant of $\mathrm{PVD}_{\mathrm{A} 506}$. The only detectable products were the chromophore-containing precursor with the original glutamic acid residue and ferribactin. Some Pseudomonas strains carry both $p t a A$ and $p v d N$ in their genome, leading to strains that are able to produce different variants of pyoverdine. On the other hand, some Pseudomonas strains have only $p v d N$ or ptaA and consequently only produce the corresponding variant ( $\alpha$-ketoglutaric acid or succinamide derivative variants) (Ringel and Brüser, 2018). PtaA can act on several different substrates, i.e. ferribactin, dihydropyoverdine and pyoverdine, which raises the question of when these enzymes operate in the periplasm (Ringel et al., 2017). The only enzyme for which the function is unknown is PvdM, which is predicted to be a dipeptidase.

Once PVDI is formed, it is secreted from the periplasm into the bacterial environment by the ATP-dependent efflux pump PvdRT-OpmQ (Hannauer et al., 2010). However, the deletion of this efflux pump does not completely abolish PVDI secretion, highly suggesting that another efflux system is involved in this process. In $P$. putida KT2440, both PvdRT-OpmQ and MdtABC-OpmB have been proposed to be involved in pyoverdine secretion (Henríquez et al., 2019). However, at least one additional efflux system participates in the export of this siderophore, as double deletion mutants for these efflux pumps still secrete pyoverdine. In P. taiwanensis type VI secretion system also appears to be involved in pyoverdine secretion, suggesting the participation of alternative secretion pathways in the export of this siderophore (Chen et al., 2016). 


\section{Organization and diversity of the pyoverdine genomic region among $\mathrm{P}$. aeruginosa strains and fluorescent Pseudomonads}

The pyoverdine region in $P$. aeruginosa strains corresponds to the region of the genome that contains all the genes involved in PVDI biosynthesis, secretion, iron acquisition and recycling (Fig. 3). This region covers approximately $50 \mathrm{~kb}$ and contains more than 30 genes. The genes are present on both DNA strands and are separated by regulator genes. Smith et al. (2005) have analysed the degree and patterns of diversity of the PDVI, PVDII and PVDIII genes in P. aeruginosa. They showed that there are three different types of gene organization, corresponding to the three structural types of pyoverdines. In addition, they found that the pyoverdine region is the most highly divergent region in the $P$. aeruginosa genome (Spencer et al., 2003; Smith et al., 2005). Interestingly, this region has unusual codon and oligonucleotide usage, indicating its acquisition by horizontal gene transfer. Among the NRPS-encoding genes, pvdL is always isolated from the three other NRPS genes, $p v d l$, pvdJ and $p v d D$, located in the central part of the region and forming a cluster. Moreover, $p v d L$ is the only NPRS enzyme that is highly conserved, whereas $p v d D$, pvdl and pvdJ display high divergence among strains, with no sequence similarity between strains. This genetic pattern directly reflects the organization of the peptide backbone of PVDI, which is always composed of two parts. The first consists of the conserved three residues L-Glu, D-Tyr and L-Dab, assembled by PvdL, with DTyr and L-Dab giving the chromophore and L-Glu the side chain, structures common to all pyoverdines. The second part is the variable peptide chain assembled by PvdD, Pvdl and PvdJ. Two other genes also display high divergence between strains in the pyoverdine region, $p v d E$ [the $A B C$ transporter involved in the transport of the pyoverdine precursor from the cytoplasm into the periplasm (Yeterian et al., 2010)] and fpvA [the outer membrane transporter involved in the uptake of ferric loaded pyoverdine (Poole et al., 1991)]. Smith et al. (2005) demonstrated that $f p v A$ shows evidence of positive selection, suggesting that $f p v A$ drives the diversity of the pyoverdine locus. Indeed, the transporter and pyoverdine peptide must coevolve to maintain mutual specificity and recognition; the evolution of $f p v A$ subsequently led to NRPS gene recombination (Ruangviriyachai et al., 2001). Finally, some genes, usually specific for the type of pyoverdine produced, are only present in certain types of $P$. aeruginosa strains. This is the case for $p v d Y I l$, which is only present in type II $P$. aeruginosa strains (Lamont et al., 2006).

The organization and diversity of the pyoverdine genomic region among fluorescent Pseudomonads was studied by Ravel and Cornelis (2003) by comparing the pyoverdine regions of $P$. aeruginosa, $P$. syringae
A
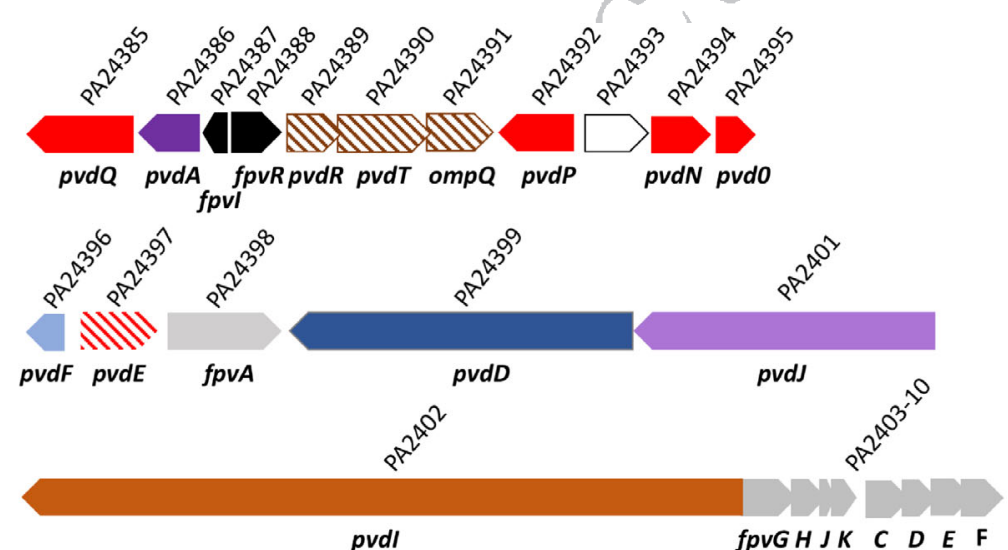

fpvA
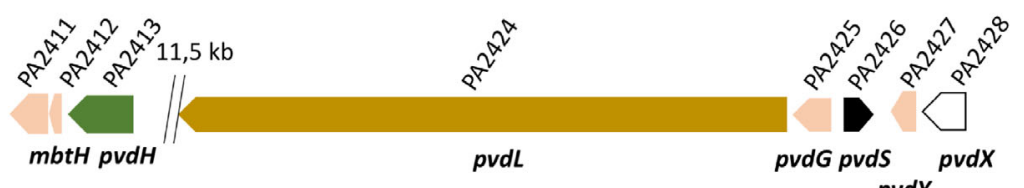

pudY

B

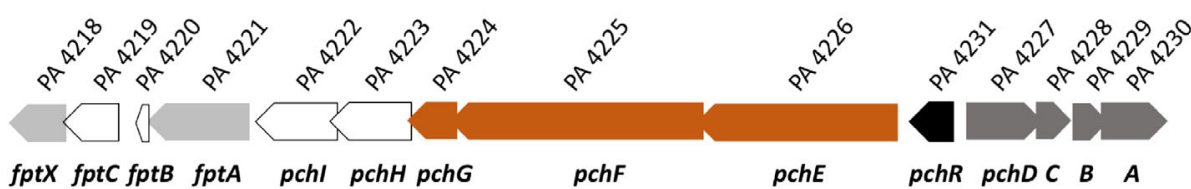

Fig. 3. Organization of PVDI genes (A) and $\mathrm{PCH}$ genes (B) on $P$. aeruginosa PAO1 genome. In both panels, coloured boxes represent the genes coding for enzymes involved in the biosynthesis of the siderophores. Dashed boxes represent the genes coding for siderophore transporters (export across the inner and outer membranes). Grey boxes represent genes involved in iron import via PVDI or $\mathrm{PCH}$ (ferri-siderophore import as well as mechanism of iron release from the siderophore and or siderophore recycling). White boxes are for genes coding for proteins of unknown function. The genes encoding the transcription regulators are represented by black boxes. Genes are represented according to their size. Double vertical lines represent an interruption in the genome of the indicated length. 
DC3000, P. fluorescens Pf0-1 and P. putida KT2440. The authors highlighted the similarities in the organization of the pyoverdine region between fluorescent Pseudomonads. Homologous genes involved in pyoverdine pathways are found in every species but the overall organization of the region is different: the pyoverdine region can form a single contiguous cluster (Owen and Ackerley, 2011) or be dispersed in the genome in three or four clusters separated by long stretches of DNA encoding genes for other functions (Ravel and Cornelis, 2003; Moon et al., 2008). In addition, the genetic context of certain genes is not conserved between Pseudomonads. For example, the pta $A$ gene in $P$. aeruginosa is located upstream of the pyoverdine region, which suggests that the PtaA enzyme may have additional functions (Ringel et al., 2017).

\section{$\mathrm{PCH}$ and Enantio-pyochelin biosynthesis}

$\mathrm{PCH}$, which is produced by all $P$. aeruginosa strains, and $\mathrm{E}-\mathrm{PCH}$, which is produced by $P$. fluorescens strains Pf-5 and $\mathrm{CHAO}$, are both condensation products of salicylate and two molecules of cysteine, with the only difference between $\mathrm{PCH}$ and E-PCH being the stereochemical configuration of the two incorporated cysteines. Consequently, E-PCH is the optical antipode or enantiomer of $\mathrm{PCH}$ (Youard et al., 2007). PCH biosynthesis involves seven cytoplasmic enzymes (two of them being NRPS), with their corresponding genes organized into two operons, pchDCBA and pchEFGHI (Fig. 3) (Serino et al., 1997; Reimmann et al., 1998). PCH biosynthesis (Fig. 4) begins with salicylate synthesis: chorismate is first transformed into isochorismate and subsequently into salicylate by the enzymes PchA (isochorismate synthase) and PchB (isochorismate-pyruvate lyase) respectively (Gaille et al., 2003; Meneely et al., 2013). Salicylate is then activated by PchD and transferred to the NRPS enzyme PchE for coupling to a molecule of cysteine under the control of PchC (Serino et al., 1997; Reimmann et al., 2004). PchC is a thioesterase that removes wrongly charged molecules from the peptidyl carrier protein domains of PchE and PchF (see below) (Reimmann et al., 2004). PchE also ensures L-Cys epimerization into D-Cys, generating dihydroaeruginoique (Dha) (Patel et al., 2003). A second molecule of cysteine is coupled to Dha by another NRPS enzyme, PchF, again under the control of PchC (Reimmann et al., 2004). This second cysteine undergoes cyclisation by the cycling module of PchF, to form nor-pyochelin, and methylation on the second thiazolidine cycle by the methylation module of PchF (Patel et al., 2003; Ronnebaum et al., 2019). The synthesized $\mathrm{PCH}$ is then released by the reductase PchG (Patel and Walsh, 2001; Reimmann et al., 2001). PCH biosynthesis occurs in the cytoplasm and nothing is currently known about $\mathrm{PCH}$ secretion or the proteins and mechanisms involved. More details concerning $\mathrm{PCH}$ biosynthesis can be found in an excellent recent review by Ronnebaum and Lamb (2018).

The biosynthesis of E-PCH in $P$. fluorescens has not yet been biochemically investigated but is probably quite similar to the $\mathrm{PCH}$ pathway in $P$. aeruginosa. A closely related gene cluster is present in the chromosome of the $P$. fluorescens strains Pf-5 and $\mathrm{CHAO}$, although the arrangement of the individual genes is different from that in $P$. aeruginosa and there is no gene with obvious sequence homology to pchG (Paulsen et al., 2005; Youard et al., 2007, 2011).

\section{Quinolobactin and thioquinolobactin biosynthesis}

Quinolobactin, an 8-hydroxy-4-methoxy-2-quinolone carboxylic acid, is produced by $P$. fluorescens ATCC17400 from xanthurenic acid. The biosynthetic pathway is still quite speculative (Fig. 4), involves at least four enzymes, and starts from xanthurenic acid (Matthijs et al., 2004). The first step requires the AMPligase QbsL, which activates the carboxylic group of xanthurenic acid via its $\mathrm{N}$-terminal domain and methylates the hydroxyl group in the fourth position via its $\mathrm{N}$ terminal methylase domain. Then, QbsCDE enzymes transfer sulphur from an unknown sulphur donor molecule to form 8-hydroxy-4-methoxy-2-quinoline thiocarboxylic acid (thioquinolobactin). The formation of this compound probably also involves the putative oxidoreductase QbsK. Quinolobactin is probably then formed by spontaneous hydrolysis of thioquinolobactin.

\section{PDTC biosynthesis}

PDTC is produced by $P$. stutzeri (Lee et al., 1999) and $P$. putida (Ockels et al., 1978) and its currently proposed biosynthetic pathway involves three major steps and five enzymes (Fig. 4) (Sepúlveda-Torre et al., 2002). It starts with the reduction of 2,3-dihydro-dipicolinic acid by the reductase Orfl into diplicolinic acid, which is then activated by OrfJ. The activated compound undergoes sulfation, probably involving the three enzymes OrfFGH, to give PDTC. The exact role of each of the three enzymes OrfFGH is still unknown.

\section{Achromobactin biosynthesis}

Achromobactin is produced by $P$. syringae and results from the condensation of one citrate molecule and one each of ethanolamine, 2,4-diaminobutyrate and $\alpha$-ketoglutarate (Fig. 4). The currently proposed scheme for the biosynthesis of achromobactin involves four enzymes and starts from citrate (Berti and Thomas, 


\section{Pyochelin biosynthesis}

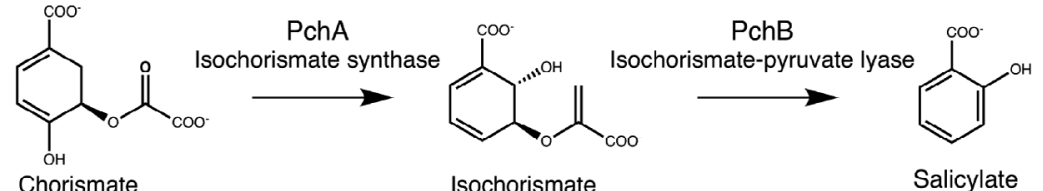

Chorismate

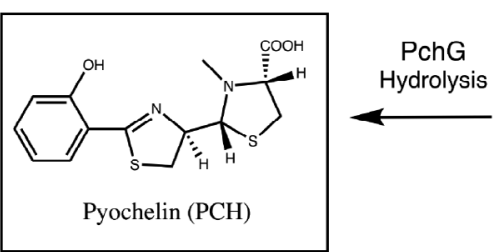

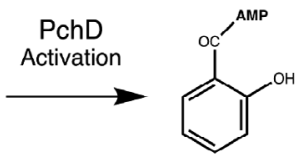

PchCE

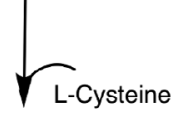

Quinolobactin and Thioquinolobactin biosynthesis
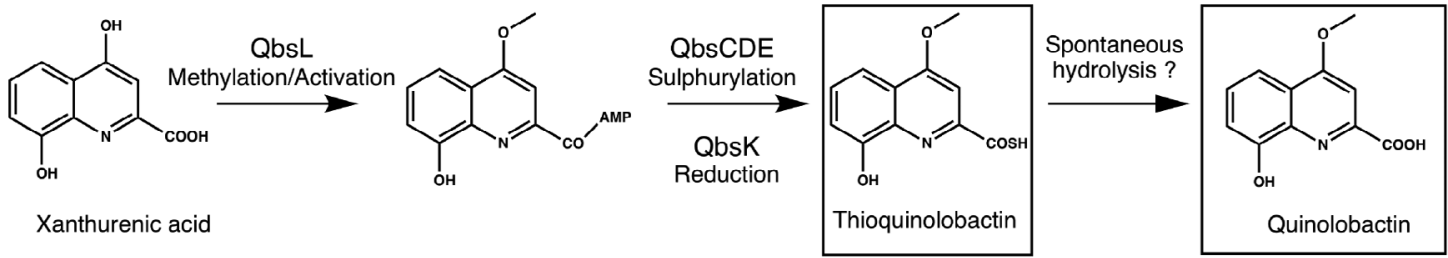

PDTC biosynthesis

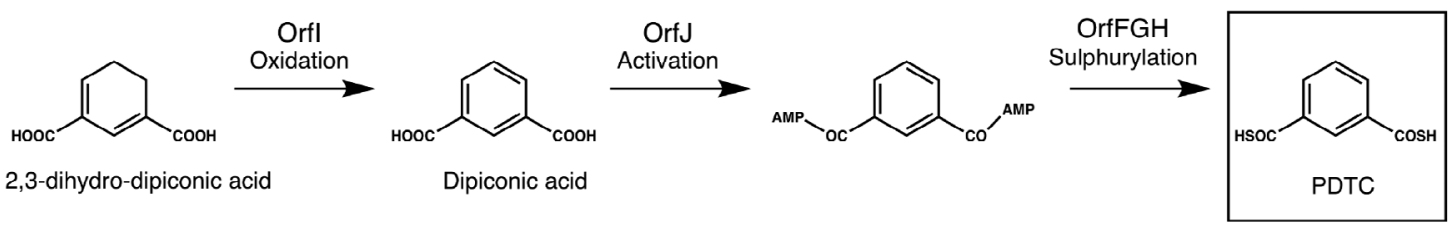

Achromobactin biosynthesis

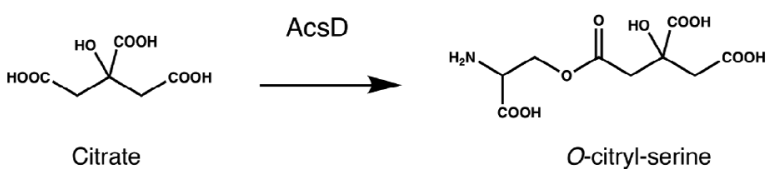

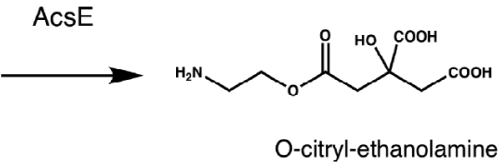

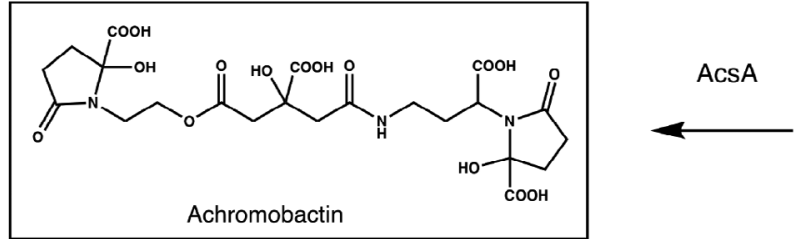

AcsE

Fig. 4. Biosynthesis pathways of pyochelin, quinolobactin, thioquinolobactin, PDTC and achromobactin. See the text for details of each biosyn- 103 thesis pathway.

2009). The first step consists of the conversion of citrate to $O$-citryl-serine by the synthetase AcsD, followed by decarboxylation by AcsE to obtain O-citryl-ethanolamine
(Schmelz et al., 2009). Then, AcsC synthetase transforms diaminobutyryl-citryl-ethanolamine into O-citryl-ethanolamine. The last step consists of the addition of two molecules 
of $\alpha$-ketoglutarate by the synthetase AcsA to give achromobactin.

\section{Cellular organization of siderophore (PVDI) biosynthesis}

Many biosynthetic pathways are based on networks of enzymes that are able to form multi-enzyme complexes (Schmitt and An, 2017), with their spatial organization depending on their protein-protein interactions. Moreover, the amount and activity of each enzyme in these biosynthetic pathways have evolved to be carefully regulated to minimize their production cost to the cells and maximize their efficiency. In $P$. aeruginosa PAO1, the enzymes involved in the cytoplasmic biosynthesis of PVDI and $\mathrm{PCH}$ have been proposed to assemble into siderosomes, i.e. siderophore-specific assemblies of enzymes involved in the synthesis of specific siderophores (Guillon et al., 2012; Imperi and Visca, 2013; Cunrath et al., 2015; Gasser et al., 2015). Siderosomes were first hypothesized for the cytoplasmic PVDI enzymes on the basis of pull-down assays using a recombinant $6 \mathrm{His}-\mathrm{PvdA}$ protein as bait to capture low amounts of the NRPS enzymes PvdJ and PvdL (Imperi and Visca, 2013). The small fraction of PvdJ and PvdL trapped by PvdA suggested transient and dynamic interactions between these proteins. PvdA was also shown to interact with the isolated M2 module of PvdJ in yeast two-hybrid experiments (Imperi and Visca, 2013). By fluorescence microscopy, PVDI-related proteins appear to be spatially organized in live cells, with clusters of PvdA colocalizing with PvdD, PvdL and PvdJ (Guillon et al., 2012; Imperi and Visca, 2013). These clusters appear as fluorescent spots located at the cell poles and are linked to iron-restriction and high levels of PVDI production (Guillon et al., 2012; Imperi and Visca, 2013). In the context of the PVDI cytoplasmic precursor, for which its biosynthesis occurs through the sequential addition of amino acids by NRPS enzymes, the interactions and spatial organization of these enzymes are thought to optimize the transfer of siderophore precursors between them and avoid their diffusion throughout the cytoplasm to prevent deleterious intra-cell metal chelation. Similar spatial patterns were observed for the $\mathrm{PCH}$ pathway, with the NRPS enzyme PchE colocalizing with PchA (Cunrath et al., 2015). PchE clustering at the bacterial poles was found to be dependent on PchA expression, whereas PchA clustering and association with the membrane was PchE-independent. This suggests a complex interplay between the various partners that form siderosomes (Cunrath et al., 2015). Classical fluorescence microscopy is constrained by the diffraction of light, which limits its spatial resolution to approximately $250-300 \mathrm{~nm}$. Given the size of Pseudomonas bacteria (rod shaped with long and short axes of approximately 1.5-2 and 0.6-0.8 $\mu \mathrm{m}$ respectively), the ability of fluorescence microscopy to provide precise and accurate information on the localization of proteins is limited. At this diffraction-limited level of resolution, proteins can localize to the same subcellular region without interacting, rendering colocalization experiments difficult to interpret.

Protein interactions in living cells can be indirectly inferred from diffusion properties, as large complexes diffuse more slowly than smaller ones or free unbound proteins. FRAP, a technique that measures the repopulation of fluorescently labelled proteins in a photobleached area, is able to quantify the two-dimensional lateral diffusion of proteins in situ (Axelrod et al., 1976) and provides information about possible interactions between proteins. FRAP has been used to characterize the diffusion properties of proteins of the PVDI siderophore pathway (Guillon et al., 2012). PvdA was found to diffuse homogeneously in the cytoplasm, with an average diffusion rate that was slightly lower than that predicted from its molecular weight and a free diffusion model. The accumulation of PvdA at the cell pole was found to be reversible, as the fluorescence of a bleached out-of-spot area in the cytoplasm completely recovered due to diffusion of fluorescent PvdA coming from the fluorescent spots (Guillon et al., 2012).

More recently, the diffusion of PvdA has been investigated using sptPALM (Gasser et al., 2020). sptPALM enables the characterization of the diffusion trajectories of single proteins with nanometric precision and high temporal resolution (Manley et al., 2008). The statistical description of thousands of single PvdA traces in live cells showed that PvdA diffuses throughout the cytoplasm, without any evident spatial constraints or structural organization at $\sim 40-\mathrm{nm}$ resolution (Fig. 5), with the exception of preferential accumulation at one pole in some cells. Heterogeneous velocities of PvdA displacements corresponded to two diffusing populations, assigned to a trapped (or restrained) fraction of PvdA (approximately 15\%) and diffusing PvdA (Fig. 5). Consistent with the transient nature of siderosomes, which associate and dissociate in vivo, these two populations were found to be exchangeable, and transition from diffusing to restrained or restrained to diffusing was observed in single traces within the time-scale of observation. Finally, the diffusion rate of the diffusing PvdA was in very good agreement with that characterized by FRAP, leading to the hypothesis that PvdA is mostly bound to complexes that can slowly diffuse throughout the cytoplasm of the cells.

Finally, the interactions of PvdA with the NRPS enzymes of the PVDI pathway were explored using Förster resonance energy transfer measured by fluorescence lifetime imaging (FLIM-FRET). FLIM-FRET 
A
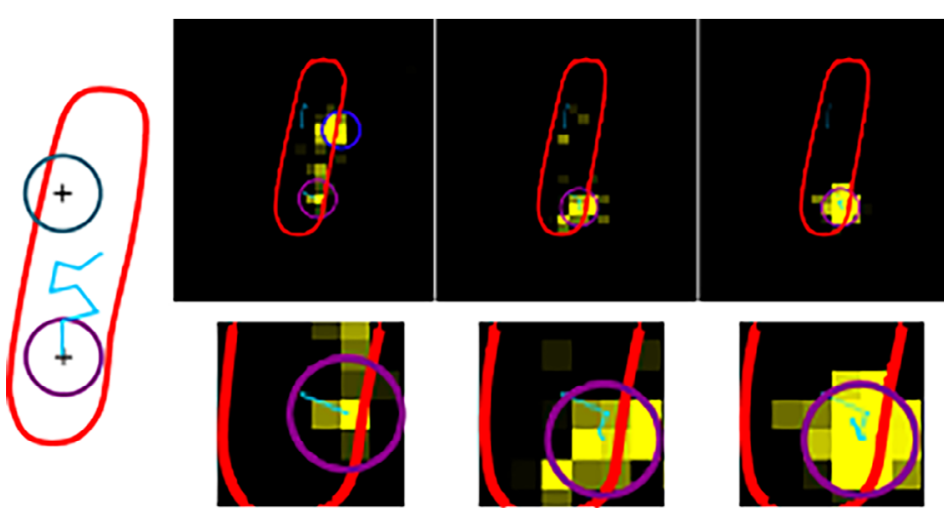

B

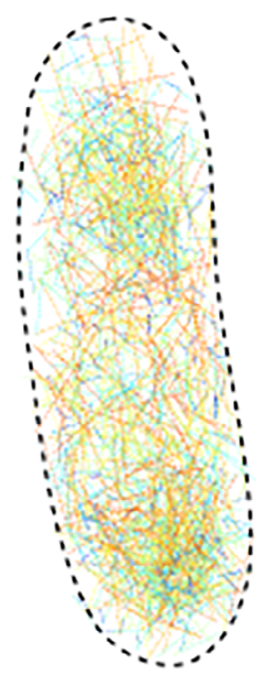

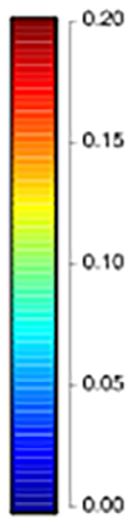

$\mu \mathrm{m}$
C

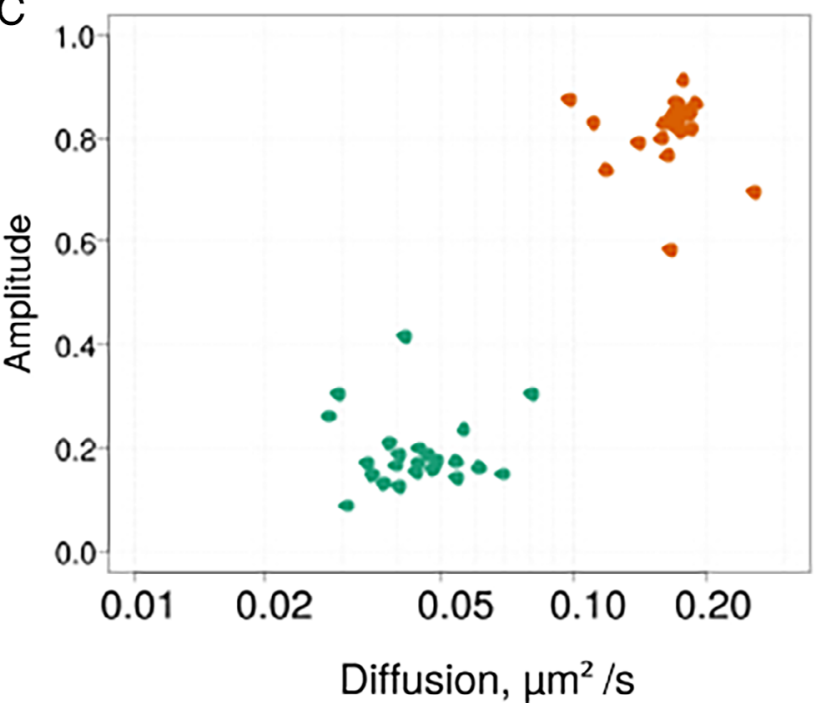

55

56

57

58

59

60

61

62

63

64

65

66

67

68

69

70

Fig. 5. Single-molecule tracking of PvdA-PAmCherry.

A. Raw fluorescence signal (upper) and focus on an ROI (lower) of a single PvdA-PAmCherry molecule in a live cell (yellow) observed over time at $62.5 \mathrm{~Hz}$. Five frames from the temporal stack of images separated by approximately $50 \mathrm{~ms}$ are represented. The contour of the bacterial cell (red overlay) was determined from the corresponding phase-contrast microscopy image. The localization of single PvdA-PAmCherry molecules is highlighted by the blue or purple overlaid circles. The size of the circle approximately corresponds to the diffraction limit $(\sim 250 \mathrm{~nm})$. The precision, which determines the uncertainty of the estimated position of the PvdA-PAmCherry, is approximately $40 \mathrm{~nm}$. The time-trace linking the localization at different time points for a given PvdA-PAmCherry molecule is represented by the cyan segments. Scale bar $=1 \mu \mathrm{m}$.

B. PvdA-PAmCherry diffusion map in a single representative cell. Approximately 2500 localizations, generating approximately 400 fluorescence traces, are represented. Each displacement step is colour coded according to the displacement jump distance since the previous frame (in micrometre).

C. Amplitude of the constrained and diffusing species of PvdA-PAmCherry as a function of their diffusion coefficients averaged per cell $(n=23$ cells, $N=3$ independent experiments) (data from Gasser et al., 2020).

enables the monitoring of protein-protein interactions and the mapping of their spatial organization in a living cell with diffraction-limited spatial resolution (Duncan et al., 2004). However, two labelled proteins that undergo FRET have to physically interact because of the strong inter-dye distance dependence required for FRET to occur and the relatively large size of fused fluorescent proteins. FRET-FLIM was used to characterize the interactions of PvdA with the four different NRPS enzymes of the PVD pathway (Gasser et al., 2020). Surprisingly, FRET-FLIM clearly showed that PvdA physically interacts with all four NRPS enzymes of the PVDI pathway in the cellular context and not only with PvdJ and/or Pvdl, the two NRPS enzymes that use fOHOrn, the molecule produced by PvdA, as a building block. Even more interestingly, the stoichiometry of the interacting complex was not the same depending on the NRPS enzyme bound by PvdA. Several PvdA molecules interacted with Pvdl, whereas PvdA formed one-to-one (or close to one-toone) complexes with PvdJ. The M2 module of PvdJ, previously identified by two-hybrid studies to be an interacting partner of PvdA (Imperi and Visca, 2013) and 
responsible for fOHOrn insertion, is a good candidate to harbour the binding site for PvdA. In contrast to PvdJ, multiple binding of PvdA to Pvdl likely fulfils the necessity for an excess of locally available substrate to optimize the activity of Pvdl. These observations also suggest that, in addition to physical coordination between active sites of tailored enzymes and NRPS modules, the colocalization of such enzymes may be sufficient to promote metabolic efficiency, making siderosomes even more relevant for efficient siderophore production.

PvdA has also been shown to have a hydrophobic, inner-membrane-anchoring domain at the $\mathrm{N}$ terminus (Meneely et al., 2009; Imperi and Visca, 2013). This association of PvdA with the inner membrane and the presence of a myristic acid chain attached to the first amino acid of the PVDI backbone (Hannauer et al., 2012b) also led to the suggestion that PVDI is synthesized on the cytoplasmic face of the inner membrane, with siderosomes associated with the inner membrane leaflet. Imperi et al. analysed isolated inner membranes of $P$. aeruginosa by matrix-assisted laser desorption/ionization time-of-flight and reported that a fraction of each of the four NRPS enzymes (PvdL, Pvdl, PvdJ and PvdD) involved in PVDI biosynthesis was associated with the inner membrane (Imperi and Visca, 2013), this was also confirmed by cell fractionation assays using fluorescent labelled NRPS of the PVDI and PCH pathways (Imperi and Visca, 2013; Cunrath et al., 2015; Gasser et al., 2015). These observations led to the hypothesis that siderosomes can exist in the bacterial cytoplasm, but they may also associate with the inner leaflet of cytoplasmic membranes (Fig. 6). Many questions about siderosomes remain unanswered, including how they interact with the inner membrane, the role of the myristic chain present in the PVDI precursor, whether and how NRPS enzymes interact with each other in siderosomes, how the organization of siderosomes affect the activity of the enzymes, whether they are always active in producing PVDI molecules and whether the enzymes involved in the biosynthetic pathways of any siderophores are organized in siderosomes.

\section{Regulation}

Siderophore production is generally highly regulated at the transcriptional level through regulation of the expression of the genes encoding the enzymes involved in their biosynthesis. Expression of these genes is repressed by the presence of iron and activated under iron-restricted conditions via molecular mechanisms that require transcriptional regulators (Cornelis et al., 2009).

Negative regulation for the biosynthesis of all the siderophores described above involves the transcriptional regulator Fur (Ferric Uptake Regulator). For a review dedicated to Fur see Fillat (2014). Fur senses the cytoplasmic concentration of $\mathrm{Fe}^{2+}$. Once the concentration of $\mathrm{Fe}^{2+}$ in the bacterial cytoplasm reaches a certain concentration, it binds to Fur and the Fur-Fe ${ }^{2+}$ complexes repress the transcription of any genes involved in iron acquisition and consequently those encoding siderophore biosynthetic enzymes (Fig. 7). Such repression involves the interaction of Fur- $\mathrm{Fe}^{2+}$ with a conserved sequence, called the Fur-box, in the promoter regions of all ironregulated genes (Escolar et al., 1999). When iron becomes limiting, fewer Fur-Fe ${ }^{2+}$ complexes form in the bacterial cytoplasm and the Fur-Fe $\mathrm{F}^{2+}$ complexes dissociate from the Fur-boxes, allowing a basal level of gene expression (Escolar et al., 1999). Fur-dependent repression has been shown for the pchDCBA, pchEFGHI genes of $\mathrm{PCH}$ biosynthesis under iron-rich conditions and for all genes of the PVDI pathways (Ochsner et al., 1995).

Conversely, under iron-restricted conditions, Fur no longer acts as a repressor. However, basal expression of the genes encoding the biosynthetic enzymes is low and positive activating loops come into play to achieve high production of pyoverdine and $\mathrm{PCH}$ siderophores. The positive regulation of $\mathrm{PCH}$ biosynthesis in $P$. aeruginosa involves the AraC transcriptional regulator $\mathrm{PchR}$, which activates transcription of the pchDCBA and pchEFGHI genes, encoding enzymes involved in $\mathrm{PCH}$ biosynthesis (Fig. 7) (Heinrichs and Poole, 1993; Heinrichs and Poole, 1996; Reimmann et al., 1998). $\mathrm{PCH}-\mathrm{Fe}^{3+}$ complexes and their uptake into the bacterial cytoplasm are required for this activation process. They act as effectors of PchR, by which PchR-PCH-Fe ${ }^{3+}$ complexes bind to the conserved PchR-box sequence in the promoter regions of the biosynthetic genes (Michel et al., 2005, 2007). Such activation allows the production of approximately $40 \mu \mathrm{M}$ of $\mathrm{PCH}$ for a culture of $P$. aeruginosa PAO1 cells of optical density at $600 \mathrm{~nm}$ of 1 , grown under iron restriction conditions (Cunrath et al., 2016). pchR transcription is itself negatively regulated by Fur and PchR itself, as the PchR box of $p c h D$ is located downstream of the $p c h R$ transcription start site (Michel et al., 2005). A similar regulatory mechanism involving a PchR regulator is involved in E-PCH production in P. fluorescens (Lin et al., 2013).

The positive autoregulation loop of PVDI biosynthesis involves a completely different mechanism than that of $\mathrm{PCH}$ biosynthesis, with transcriptional regulators of another family (Fig. 7): two cytoplasmic sigma factors (PvdS and Fpvl) and the inner membrane anti-sigma factor (FpvR) (Visca, 2004; Llamas et al., 2014). PvdS activates the transcription of PVDI biosynthetic genes, as well as some that encode virulence factors (Prince et al., 1993; Cunliffe et al., 1995; Ochsner et al., 1996; Vasil et al., 1998; Wilson and Lamont, 2000; Wilderman et al., 2001; Visca, 2004; Gaines et al., 2007), while Fpvl 


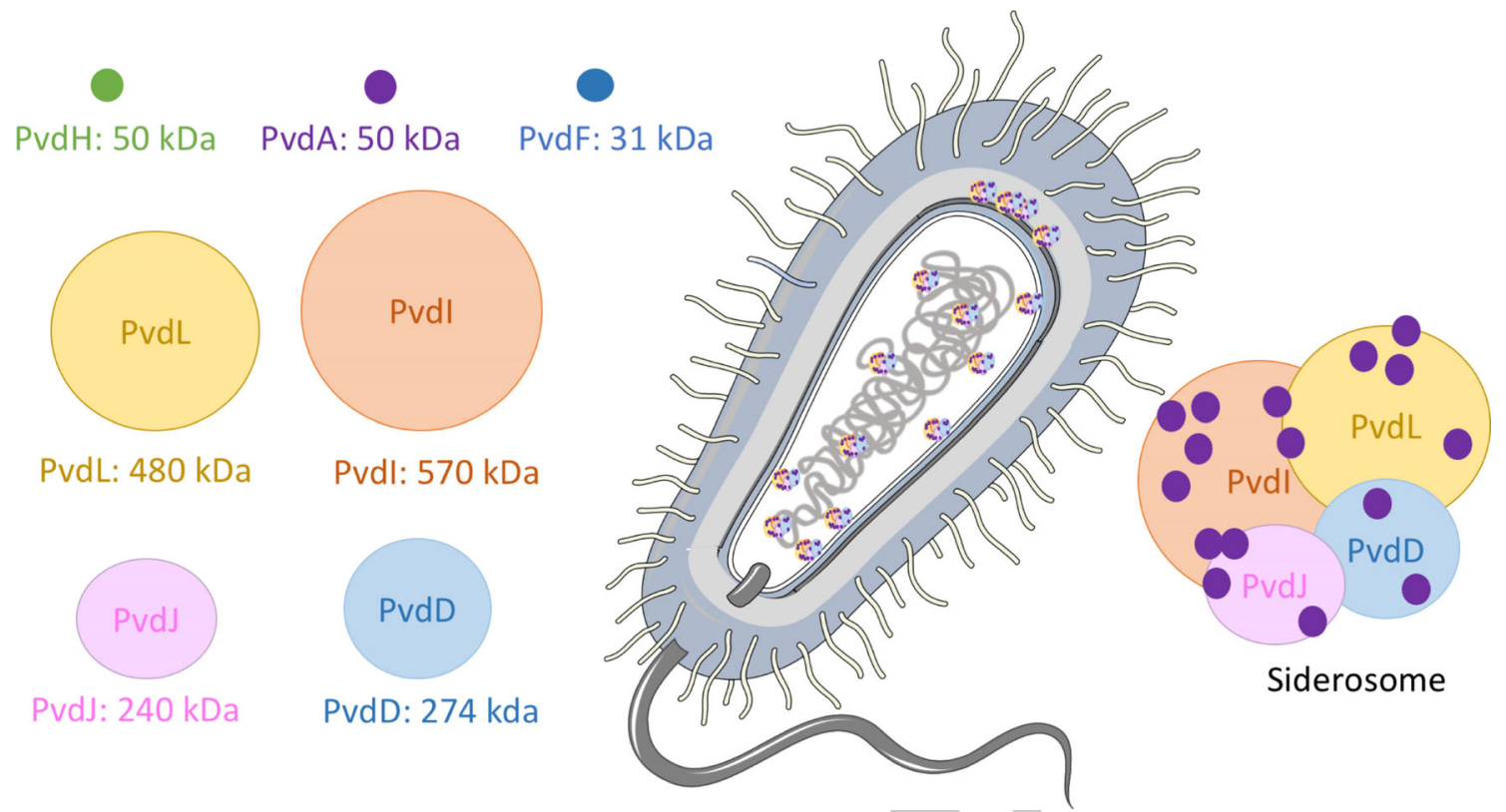

Fig. 6. Scheme of the siderosome involved in PVDI biosynthesis. The seven enzymes involved in the cytoplasmic biosynthesis of the PVDI precursor are represented. The four NRPS (PvdL, Pvdl, PvdJ and PvdD) are responsible for the synthesis of the 11 amino acid peptides, and PvdH, $\mathrm{PvdA}$ and PvdF are the accessory proteins involved in the synthesis of L-Dab and L-fOH Orn. Enzyme diameters are proportional to their molecular weight (MW). On the right of the figure a schematic view of the enzymatic complex called siderosome (for more details see the text).

activates transcription of the fpvA gene, encoding the outer membrane transporter that imports PVDI-Fe ${ }^{3+}$ complexes from the environment (Redly and Poole, 2003; Redly and Poole, 2005). Broadly [for more details see the reviews (Llamas et al., 2014)], this regulatory mechanism first requires the binding of PVDI-Fe to the outer membrane transporter FpvA, which leads to the interaction of the periplasmic domain of FpvA with the inner membrane anti-sigma factor FpvR (Brillet et al., 2007), resulting in the release of the sigma factors PvdS and Fpvl into the cytoplasm. They then activate transcription of the genes that they regulate, such as those that encode PVDI biosynthetic enzymes, resulting in an increase in PVDI production (Wilson et al., 2001; Redly and Poole, 2003, 2005; Spencer et al., 2008; Draper et al., 2011; Bastiaansen et al., 2015). If PVDI is unable to chelate $\mathrm{Fe}^{3+}$ in the bacterial environment, FpvR sequesters most of the Fpvl and PvdS present in the bacterial cells, blocking activation of the transcription of the regulated genes (Redly and Poole, 2005; Minandri et al., 2016). However, as less FpvR is expressed than sigma factors in $P$. aeruginosa cells, basal levels of PvdS and Fpvl are still present in the cytoplasm, resulting in a low level of PVDI production that can prime activation of the regulatory loop (Edgar et al., 2017). Such regulation of pyoverdine production involving sigma and anti-sigma factors is also used by other fluorescent Pseudomonads, such as $P$. putida and $P$. protegens (Llamas et al., 2014). Signals other than the iron concentration, such as the level of bis- $\left(3^{\prime}-5^{\prime}\right)$-cyclic dimeric guanosine monophosphate, phosphate starvation, sulphur availability, biofilm formation, and alginate production and other transcriptional regulators have been shown to regulate PVDI production in $P$. aeruginosa PAO1 cells. However, the molecular mechanisms have not yet been clearly elucidated (Delic-Attree et al., 1997; Zaborin et al., 2009; Imperi et al., 2010; Balasubramanian et al., 2014; Chen et al., 2015). Under strong iron-restricted conditions, PVDI production can reach concentrations of approximately $80 \mu \mathrm{M}$ for a culture of $P$. aeruginosa cells of an optical density at $600 \mathrm{~nm}$ of (iron restriction growth conditions) (Cunrath et al., 2016).

Moreover, several studies have shown that the presence of metals other than iron in the bacterial environment can also modulate the bacterial production of siderophores (Huyer and Page, 1988; Hofte et al., 1993; $\mathrm{Hu}$ and Boyer, 1996). In P. aeruginosa, no metals are able to significantly activate PVDI or $\mathrm{PCH}$ production above that induced by iron restriction (Carballido Lopez et al., 2019). However, $\mathrm{PCH}$ synthesis in $P$. aeruginosa is repressed by $\mathrm{Co}^{2+}$ and $\mathrm{Ni}^{2+}$, with the same efficiency as that by $\mathrm{Fe}^{3+}$ for $\mathrm{Co}^{2+}$ (Carballido Lopez et al., 2019). As described above, the transcriptional repressor Fur becomes loaded with ferrous iron in the presence of increasing $\mathrm{Fe}^{3+}$ concentrations and represses the expression of all pch genes. Fur is not involved in the decrease of $\mathrm{PCH}$ production in the presence of increasing $\mathrm{Co}^{2+}$ or $\mathrm{Ni}^{2+}$ concentrations, but rather the transcriptional activator PchR (Carballido Lopez et al., 2019). This 


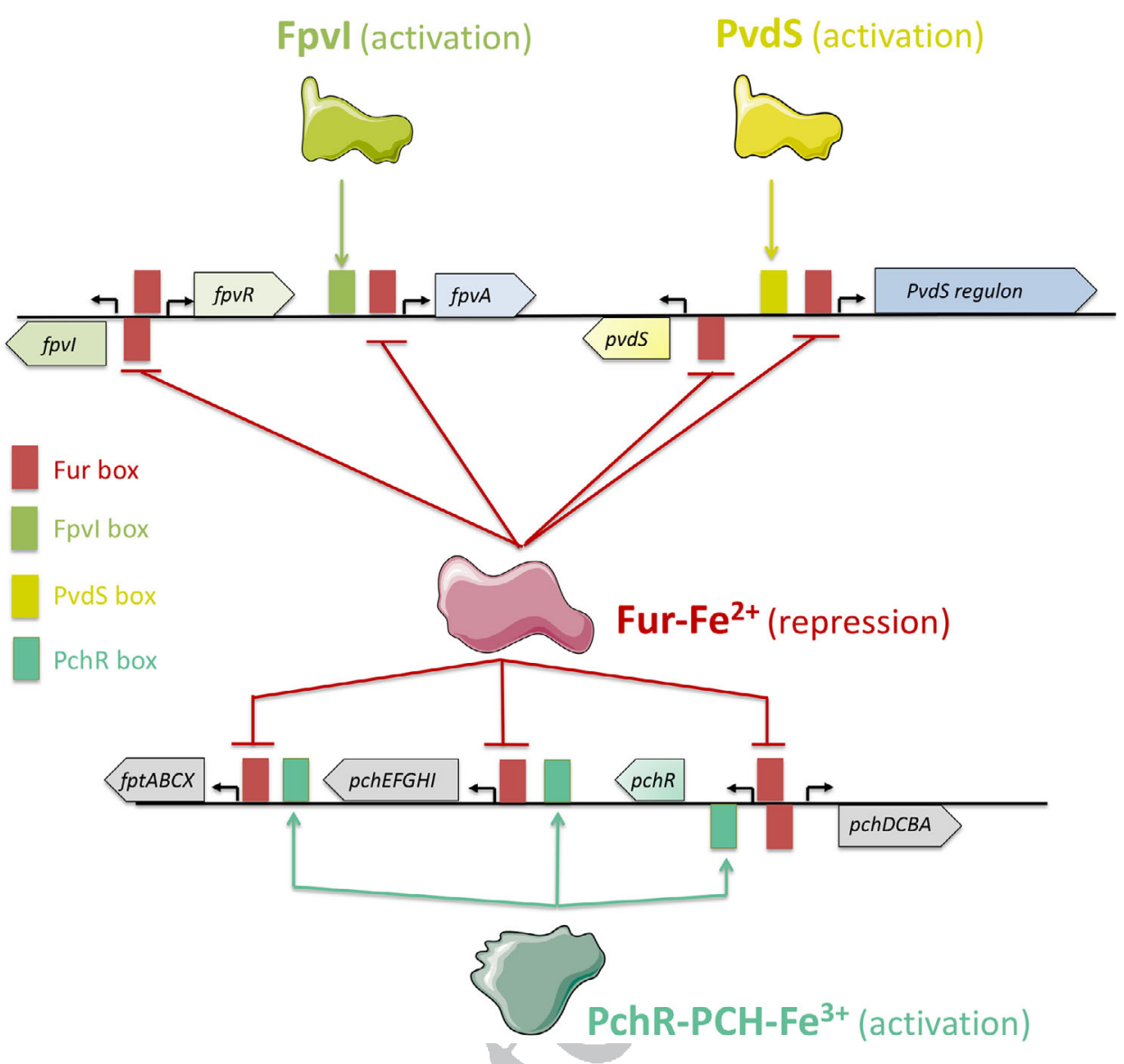

Fig. 7. Transcriptional regulation of genes coding for proteins involved in the PVDI and PCH iron-uptake pathways. Under iron-restricted conditions, transcription of the genes of the $\mathrm{PCH}$ pathway is activated via the transcriptional regulator $\mathrm{PchR}$. This protein, in a complex with $\mathrm{PCH}-\mathrm{Fe}^{3+}$, activates the transcription of all the genes of the PCH pathway, except $p c h R$, by interacting with the PchR box. In the PVDI pathway, two sigma factors, PvdS and Fpvl, are involved in activation of the transcription of the genes of the pvd locus. Fpvl activates the transcription of only fpvA, the outer membrane importer of ferri-PVDI. PvdS activates the transcription of all other genes, except $p v d S$, fpvl and fpvR (FpvR being the antisigma factor of PvdS and Fpvl). In the presence of iron, gene transcription in both pathways is repressed by the transcriptional regulator Fur in a complex with $\mathrm{Fe}^{2+}$. The Fur-Fe ${ }^{2+}$ complex binds to the Fur box in the promoter region of the various genes and operons encoding the enzymes involved in PVD and PCH biosynthesis and also represses transcription of the transcriptional regulators PvdS, Fpvl and PchR. For more details see the text.

regulator becomes loaded with $\mathrm{PCH}-\mathrm{Co}$ and $\mathrm{PCH}-\mathrm{Ni}$, as both complexes can enter bacterial cells. Consequently, PchR is no longer able to activate transcription of the pch genes due to a decrease in the intracellular concentration of PchR-PCH-Fe complexes. The repression of $\mathrm{PCH}$ production in the presence of $\mathrm{Co}^{2+}$, and probably that of $\mathrm{Ni}^{2+}$, is due to a non-specific interaction of $\mathrm{PCH}-$ Co with PchR, which is no longer able to activate $\mathrm{PCH}$ production.

At last, once all the enzymes involved in the biosynthesis of a siderophore are expressed, the regulation of their enzymatic activity may also be regulated. However, nothing is known yet about such a possible regulation. The organization in siderosomes could play such a regulating role. Moreover, bacteria live in communities with some producing siderophores and some acting as cheater (do not produce siderophores but use those produced by other bacteria); such social interactions in communities also affect the regulation of siderophore production (Butait et al., 2017; Granato and Kümmerli, 2017; Butait\ et al., 2018; Özkaya et al., 2018; Stilwell et al., 2018). This question needs to be investigated further in the future at the level of diverse communities involving different Pseudomonads but also other bacterial species since $P$. aeruginosa is able to use many different siderophores produced by other bacteria (exosiderophores) (Cornelis and Matthijs, 2002; Cornelis and Dingemans, 2013). It has been shown that the presence of exosiderophores clearly impacts the expression levels of the proteins of the different iron uptake pathways of $P$. aeruginosa (Llamas et al., 2006, 2008; Perraud et al., 2020).

\section{Conclusions}

Siderophore biosynthetic pathways can be highly complex, involving highly diverse enzymes. We now have 
precise knowledge of the various enzymatic steps involved in the PVDI and PCH pathways. However, many questions remain for most of the biosynthesis pathways of the other siderophores produced by fluorescent Pseudomonads and a major effort is also necessary to unravel all the existing subtleties and variations in the biosynthesis of the divers pyoverdines produced by these bacteria. The cellular organization of these enzymes, their distribution in the bacterial cells, the existence of siderosomes and the diverse protein interactions involved in these potential enzymatic complexes also still raise many questions and concerns. Having precise knowledge of the biosynthetic pathways of siderophores can be a true asset in biotechnology. Indeed, because of the strong metal chelating properties of these compounds and their importance in bacterial iron homeostasis, siderophores have many applications in either biomedical (Bedford et al., 2013; Mislin and Schalk, 2014; Schalk and Mislin, 2017; Schalk, 2018) or bioremediation (Cornu et al., 2014; Ferret et al., 2014; Hazotte et al., 2018) approaches.

\section{References}

Ackerley, D.F., Caradoc-Davies, T.T., and Lamont, I.L. (2003) Substrate specificity of the nonribosomal peptide synthetase PvdD from Pseudomonas aeruginosa. $J$ Bacteriol 185: 2848-2855.

Ahmadi, M.K., Fawaz, S., Jones, C.H., Zhang, G., and Pfeifer, B.A. (2015) Total biosynthesis and diverse applications of the nonribosomal peptide-polyketide siderophore yersiniabactin. Appl Environ Microbiol 81: 5290-5298.

Albrecht-Gary, A.M., Blanc, S., Rochel, N., Ocacktan, A.Z., and Abdallah, M.A. (1994) Bacterial iron transport: coordination properties of pyoverdin $\mathrm{PaA}$, a peptidic siderophore of Pseudomonas aeruginosa. Inorg Chem 33: 6391-6402.

Axelrod, D., Koppel, D.E., Schlessinger, J., Elson, E., and Webb, W.W. (1976) Mobility measurement by analysis of fluorescence photobleaching recovery kinetics. Biophys $J$ 16: 1055-1069.

Balasubramanian, D., Kumari, H., Jaric, M., Fernandez, M., Turner, K.H., Dove, S.L., et al. (2014) Deep sequencing analyses expands the Pseudomonas aeruginosa AmpR regulon to include small RNA-mediated regulation of iron acquisition, heat shock and oxidative stress response. Nucleic Acids Res 42: 979-998.

Banin, E., Vasil, M.L., and Greenberg, E.P. (2005) Iron and Pseudomonas aeruginosa biofilm formation. Proc Natl Acad Sci U S A 102: 11076-11081.

Bastiaansen, K.C., Otero-Asman, J.R., Luirink, J., Bitter, W., and Llamas, M.A. (2015) Processing of cell-surface signalling anti-sigma factors prior to signal recognition is a conserved autoproteolytic mechanism that produces two functional domains. Environ Microbiol 17: 3263-3277.

Baysse, C., De Vos, D., Naudet, Y., Vandermonde, A., Ochsner, U., Meyer, J.M., et al. (2000) Vanadium interferes with siderophore-mediated iron uptake in Pseudomonas aeruginosa. Microbiology 146: 2425-2434.

Bedford, M.R., Ford, S.J., Horniblow, R.D., Iqbal, T.H., and Tselepis, C. (2013) Iron chelation in the treatment of cancer: a new role for deferasirox? J Clin Pharmacol 53: 885-891.

Berti, A.D., and Thomas, M.G. (2009) Analysis of achromobactin biosynthesis by Pseudomonas syringae pv. syringae B728a. J Bacteriol 191: 4594-4604.

Boll, B., Taubitz, T., and Heide, L. (2011) Role of MbtH-like proteins in the adenylation of tyrosine during aminocoumarin and vancomycin biosynthesis. J Biol Chem 286: 36281-36290.

Boukhalfa, H., and Crumbliss, A.L. (2002) Chemical aspects od siderophore mediated iron transport. Biometals 15: 325-339.

Brandel, J., Humbert, N., Elhabiri, M., Schalk, I.J., Mislin, G. L.A., and Albrecht-Garry, A.-M. (2012) Pyochelin, a siderophore of Pseudomonas aeruginosa: physicochemical characterization of the iron(III), copper(II) and zinc(II) complexes. Dalton Trans 41: 2820-2834.

Braud, A., Hannauer, M., Mislin, G.L.A., and Schalk, I.J. (2009a) The Pseudomonas aeruginosa pyochelin-iron uptake pathway and its metal specificity. $J$ Bacteriol 191: 5317-5325.

Braud, A., Hoegy, F., Jezequel, K., Lebeau, T., and Schalk, I.J. (2009b) New insights into the metal specificity of the Pseudomonas aeruginosa pyoverdine-iron uptake pathway. Environ Microbiol 11: 1079-1091.

Brillet, K., Journet, L., Celia, H., Paulus, L., Stahl, A., Pattus, F., and Cobessi, D. (2007) A $\beta$-strand lockexchange for signal transduction in TonB-dependent transducers on the basis of a common structural motif. Structure 15: 1383-1391.

Budzikiewicz, H. (1997) Siderophores of fluorescent pseudomonads. Z Naturforsch C 52: 713-720.

Budzikiewicz, H. (2004) Siderophores of the Pseudomonadaceae sensu stricto (fluorescent and nonfluorescent Pseudomonas spp.). Fortschritte der Chemie organischer Naturstoffe. Prog Chem Org Nat Prod 87: 81-237.

Budzikiewicz, H., Schafer, M., Fernandez, D.U., Matthijs, S., and Cornelis, P. (2007) Characterization of the chromophores of pyoverdins and related siderophores by electrospray tandem mass spectrometry. Biometals 20: 135-144.

Butaitð, E., Baumgartner, M., Wyder, S., and Kümmerli, R. (2017) Siderophore cheating and cheating resistance shape competition for iron in soil and freshwater Pseudomonas communities. Nat Commun 8: 414.

Butait】, E., Kramer, J., Wyder, S., and Kümmerli, R. (2018) Environmental determinants of pyoverdine production, exploitation and competition in natural Pseudomonas communities. Environ Microbiol 20: 3629-3642.

Carballido Lopez, A., Cunrath, O., Forster, A., Pérard, J., Graulier, G., Legendre, R., et al. (2019) Non-specific interference of cobalt with siderophore-dependent iron uptake pathways. Metallomics 11: 1937-1951.

Cézard, C., Farvacques, N., and Sonnet, P. (2015) Chemistry and biology of pyoverdines, Pseudomonas primary siderophores. Curr Med Chem 22: 165-186. 
Chen, W.-J., Kuo, T.-Y., Hsieh, F.-C., Chen, P.-Y., Wang, C.S., Shih, Y.-L., et al. (2016) Involvement of type VI secretion system in secretion of iron chelator pyoverdine in Pseudomonas taiwanensis. Sci Rep 6: 32950.

Chen, Y., Yuan, M., Mohanty, A., Yam, J.K.H., Liu, Y., Chua, S.L., et al. (2015) Multiple diguanylate cyclasecoordinated regulation of pyoverdine synthesis in Pseudomonas aeruginosa. Environ Microbiol Rep 7: 498-507.

Cornelis, P. (2010) Iron uptake and metabolism in pseudomonads. Appl Microbiol Biotechnol 86: 1637-1645.

Cornelis, P., and Dingemans, J. (2013) Pseudomonas aeruginosa adapts its iron uptake strategies in function of the type of infections. Front Cell Infect Microbiol 3: 75.

Cornelis, P., and Matthijs, S. (2002) Diversity of siderophoremediated iron uptake systems in fluorescent pseudomonads: not only pyoverdines. Environ Microbiol 4: 787-798.

Cornelis, P., Matthijs, S., and Van Oeffelen, L. (2009) Iron uptake regulation in Pseudomonas aeruginosa. Biometals 22: 15-22.

Cornu, J.Y., Elhabiri, M., Ferret, C., Geoffroy, V.A., Jezequel, K., Leva, Y., et al. (2014) Contrasting effects of pyoverdine on the phytoextraction of $\mathrm{Cu}$ and $\mathrm{Cd}$ in a calcareous soil. Chemosphere 103: 212-219.

Cox, C.D., Rinehart, K.L., Jr., Moore, M.L., and Cook, J.C., Jr. (1981) Pyochelin: novel structure of an iron-chelating growth promoter for Pseudomonas aeruginosa. Proc Natl Acad Sci U S A 78: 4256-4260.

Cunliffe, H.E., Merriman, T.R., and Lamont, I.L. (1995) Cloning and characterization of $p v d S$, a gene required for pyoverdine synthesis in Pseudomonas aeruginosa: PvdS is probably an alternative sigma factor. $J$ Bacteriol 177: 2744-2750.

Cunrath, O., Gasser, V., Hoegy, F., Reimmann, C., Guillon, L., and Schalk, I.J. (2015) A cell biological view of the siderophore pyochelin iron uptake pathway in Pseudomonas aeruginosa. Environ Microbiol 17: 171-185.

Cunrath, O., Geoffroy, V.A., and Schalk, I.J. (2016) Metallome of Pseudomonas aeruginosa: a role for siderophores. Environ Microbiol 18: 3258-3267.

Delic-Attree, I., Toussaint, B., Garin, J., and Vignais, P.M. (1997) Cloning, sequence and mutagenesis of the structural gene of Pseudomonas aeruginosa CysB, which can activate algD transcription. Mol Microbiol 24: 1275-1284.

Demange, P., Wendenbaum, S., Linget, C., Mertz, C., Cung, M.T., Dell, A., and Abdallah, M.A. (1990) Bacterial siderophores: structure and NMR assigment of pyoverdins $\mathrm{PaA}$, siderophores of Pseudomonas aeruginosa ATCC 15692. Biol Met 3: 155-170.

Dorrestein, P., and Begley, T.P. (2005) Oxidative cascades: a facile biosynthetic strategy for the assembly of complex molecules. Bioorg Chem 33: 136-148.

Dorrestein, P.C., Poole, K., and Begley, T.P. (2003) Formation of the chromophore of the pyoverdine siderophores by an oxidative cascade. Org Lett 5: 2215-2217.

Drake, E.J., Cao, J., Qu, J., Shah, M.B., Straubinger, R.M., and Gulick, A.M. (2007) The 1.8 A crystal structure of $\mathrm{PA} 2412$, an $\mathrm{MbtH}$-like protein from the pyoverdine cluster of Pseudomonas aeruginosa. J Biol Chem 282: 20425-20434.

Drake, E.J., and Gulick, A.M. (2011) Structural characterization and high-throughput screening of inhibitors of PvdQ, an NTN hydrolase involved in pyoverdine synthesis. ACS Chem Biol 6: 1277-1286.

Drake, E.J., and Gulick, A.M. (2016) 1.2 Å resolution crystal structure of the periplasmic aminotransferase PvdN from Pseudomonas aeruginosa. Acta Crystallogr F Struct Biol Commun 72: 403-408.

Draper, R.C., Martin, L.W., Beare, P.A., and Lamont, I.L. (2011) Differential proteolysis of sigma regulators controls cell-surface signalling in Pseudomonas aeruginosa. Mol Microbiol 82: 1444-1453.

Duncan, R.R., Bergmann, A., Cousin, M.A., Apps, D.K., and Shipston, M.J. (2004) Multi-dimensional time-correlated single photon counting (TCSPC) fluorescence lifetime imaging microscopy (FLIM) to detect FRET in cells. $J$ Microsc 215: 1-12.

Edgar, R.J., Hampton, G.E., Garcia, G.P.C., Maher, M.J., Perugini, M.A., Ackerley, D.F., and Lamont, I.L. (2017) Integrated activities of two alternative sigma factors coordinate iron acquisition and uptake by Pseudomonas aeruginosa. Mol Microbiol 106: 891-904.

Escolar, L., Perez-Martin, J., and de Lorenzo, V. (1999) Opening the iron box: transcriptional metalloregulation by the fur protein. J Bacteriol 181: 6223-6229.

Felnagle, E.A., Barkei, J.J., Park, H., Podevels, A.M., McMahon, M.D., Drott, D.W., and Thomas, M.G. (2010) $\mathrm{MbtH}$-like proteins as integral components of bacterial nonribosomal peptide synthetases. Biochemistry 49: 8815-8817.

Ferret, C., Cornu, J.Y., Elhabiri, M., Sterckeman, T., Braud, A., Jezequel, K., et al. (2014) Effect of pyoverdine supply on cadmium and nickel complexation and phytoavailability in hydroponics. Environ Sci Pollut Res Int 22: 2106-2116.

Fillat, M.F. (2014) The FUR (ferric uptake regulator) superfamily: diversity and versatility of key transcriptional regulators. Arch Biochem Biophys 546: 41-52.

Folschweiller, N., Gallay, J., Vincent, M., Abdallah, M.A., Pattus, F., and Schalk, I.J. (2002) The interaction between pyoverdin and its outer membrane receptor in Pseudomonas aeruginosa leads to different conformers: a timeresolved fluorescence study. Biochemistry 41: 14591-14601.

Franza, T., Mahe, B., and Expert, D. (2005) Erwinia chrysanthemi requires a second iron transport route dependent of the siderophore achromobactin for extracellular growth and plant infection. Mol Microbiol 55: 261-275.

Fuchs, R., and Budzikiewicz, H. (2001) Structural studies of pyoverdins by mass spectrometry. Curr Org Chem 5: 265-288.

Fuchs, R., Schafer, M., Geoffroy, V., and Meyer, J.M. (2001) Siderotyping--a powerful tool for the characterization of pyoverdines. Curr Top Med Chem 1: 31-57.

Gaille, C., Reimmann, C., and Haas, D. (2003) Isochorismate synthase $(\mathrm{Pch} A)$, the first and rate-limiting enzyme in salicylate biosynthesis of Pseudomonas aeruginosa. J Biol Chem 278: 16893-16898.

Gaines, J.M., Carty, N.L., Tiburzi, F., Davinic, M., Visca, P., Colmer-Hamood, J.A., and Hamood, A.N. (2007) Regulation of the Pseudomonas aeruginosa toxA, regA and $p t x R$ genes by the iron-starvation sigma factor PvdS under reduced levels of oxygen. Microbiology 153: 4219-4233. 
1 Gasser, V., Guillon, L., Cunrath, O., and Schalk, I.J. (2015) Cellular organization of siderophore biosynthesis in Pseudomonas aeruginosa: evidence for siderosomes. J Inorg Biochem 148: 27-34.

Gasser, V., Malrieu, M., Forster, A., Mély, Y., Schalk, I.J., and Godet, J. (2020) In cellulo FRET-FLIM and single molecule tracking reveal the supra-molecular organization of the pyoverdine bio-synthetic enzymes in Pseudomonas aeruginosa. Q Rev Biophys 53: e1.

Ge, L., and Seah, S.Y. (2006) Heterologous expression, purification, and characterization of an l-ornithine $\mathrm{N}(5)$ hydroxylase involved in pyoverdine siderophore biosynthesis in Pseudomonas aeruginosa. J Bacteriol 188: 7205-7210.

Granato, E.T., and Kümmerli, R. (2017) The path to reevolve cooperation is constrained in Pseudomonas aeruginosa. BMC Evol Biol 17: 214.

Greenwald, J., Nader, M., Celia, H., Gruffaz, C., Geoffroy, V., Meyer, J.M., et al. (2009) FpvA bound to non-cognate pyoverdines: molecular basis of siderophore recognition by an iron transporter. Mol Microbiol 72: 1246-1259.

Guillon, L., Altenburger, S., Graumann, P.L., and Schalk, I.J. (2013) Deciphering protein dynamics of the siderophore pyoverdine pathway in Pseudomonas aeruginosa. PLoS One 8: e79111.

Guillon, L., El Mecherki, M., Altenburger, S., Graumann, P. L., and Schalk, I.J. (2012) High cellular organisation of pyoverdine biosynthesis in Pseudomonas aeruginosa: localization of PvdA at the old cell pole. Environ Microbiol 14: 1982-1994.

Gulick, A.M. (2017) Nonribosomal peptide synthetase biosynthetic clusters of ESKAPE pathogens. Nat Prod Rep 34: 981-1009.

Handfield, M., Lehoux, D.E., Sanschagrin, F., Mahan, M.J., Woods, D.E., and Levesque, R.C. (2000) In vivo-induced genes in Pseudomonas aeruginosa. Infect Immun 68: 2359-2362.

Hannauer, M., Braud, A., Hoegy, F., Ronot, P., Boos, A., and Schalk, I.J. (2012a) The PvdRT-OpmQ efflux pump controls the metal selectivity of the iron uptake pathway mediated by the siderophore pyoverdine in Pseudomonas aeruginosa. Environ Microbiol 14: 1696-1708.

Hannauer, M., Schäfer, M., Hoegy, F., Gizzi, P., Wehrung, P., Mislin, G.L.A., et al. (2012b) Biosynthesis of the pyoverdine siderophore of Pseudomonas aeruginosa involves precursors with a myristic or a myristoleic acid chain. FEBS Lett 586: 96-101.

Hannauer, M., Yeterian, E., Martin, L.W., Lamont, I.L., and Schalk, I.J. (2010) Secretion of newly synthesized pyoverdine by Pseudomonas aeruginosa involves an efflux pump. FEBS Lett 584: 4751-4755.

Hazotte, A., Péron, O., Gaudin, P., Abdelouas, A., and Lebeau, T. (2018) Effect of Pseudomonas fluorescens and pyoverdine on the phytoextraction of cesium by red clover in soil pots and hydroponics. Environ Sci Pollut Res Int 25: 20680-20690.

Heinrichs, D.E., and Poole, K. (1993) Cloning and sequence analysis of a gene (pchR) encoding an AraC family activator of pyochelin and ferripyochelin receptor synthesis in Pseudomonas aeruginosa. J Bacteriol 175: 5882-5889.
Heinrichs, D.E., and Poole, K. (1996) PchR, a regulator of ferripyochelin receptor gene ( $f p t A)$ expression in Pseudomonas aeruginosa, functions both as an activator and as a repressor. J Bacteriol 178: 2586-2592.

Henríquez, T., Stein, N.V., and Jung, H. (2019) PvdRTOpmQ and MdtABC-OpmB efflux systems are involved in pyoverdine secretion in Pseudomonas putida KT2440. Environ Microbiol Rep 11: 98-106.

Hoegy, F., Lee, X., Noël, S., Mislin, G.L., Rognan, D., Reimmann, C., and Schalk, I.J. (2009) Stereospecificity of the siderophore pyochelin outer membrane transporters in fluorescent Pseudomonads. J Biol Chem 284: 14949-14957.

Hofte, M., Buysens, S., Koedam, N., and Cornelis, P. (1993) Zinc affects siderophore-mediated high affinity iron uptake systems in the rhizosphere Pseudomonas aeruginosa 7NSK2. Biometals 6: 85-91.

Hohlneicher, U., Schäfer, M., Fuchs, R., and Budzikiewicz, H. (2001) Ferribactins as the biogenetic precursors of Pseudomonas siderophores pyoverdins. $Z$ Naturforsch C 56c: 308-310.

Hu, X., and Boyer, G.L. (1996) Siderophore-mediated aluminum uptake by Bacillus megaterium ATCC 19213. Appl Environ Microbiol 62: 4044-4048.

Hur, G.H., Vickery, C.R., and Burkart, M.D. (2012) Explorations of catalytic domains in non-ribosomal peptide synthetase enzymology. Nat Prod Rep 29: 1074-1098.

Huyer, M., and Page, W.J. (1988) Zn increases Siderophore production in Azotobacter vinelandii. Appl Environ Microbiol 54: 2625-2631.

Imperi, F., Tiburzi, F., Fimia, G.M., and Visca, P. (2010) Transcriptional control of the pvdS iron starvation sigma factor gene by the master regulator of sulfur metabolism CysB in Pseudomonas aeruginosa. Environ Microbiol 12: 1630-1642.

Imperi, F., and Visca, P. (2013) Subcellular localization of the pyoverdine biogenesis machinery of Pseudomonas aeruginosa: a membrane-associated "siderosome". FEBS Lett 587: 3387-3391.

Izoré, T., and Cryle, M.J. (2018) The many faces and important roles of protein-protein interactions during nonribosomal peptide synthesis. Nat Prod Rep 35: 1120-1139.

Jones, A.M., Lindow, S.E., and Wildermuth, M.C. (2007) Salicylic acid, yersiniabactin, and pyoverdin production by the model phytopathogen Pseudomonas syringae pv. tomato DC3000: synthesis, regulation, and impact on tomato and Arabidopsis host plants. J Bacteriol 189: 6773-6786.

Lamont, I.L., and Martin, L.W. (2003) Identification and characterization of novel pyoverdine synthesis genes in Pseudomonas aeruginosa. Microbiology 149: 833-842.

Lamont, I.L., Martin, L.W., Sims, T., Scott, A., and Wallace, M. (2006) Characterization of a gene encoding an acetylase required for pyoverdine synthesis in Pseudomonas aeruginosa. J Bacteriol 188: 3149-3152.

Lee, C.H., Lewis, T.A., Paszczynski, A., and Crawford, R.L. (1999) Identification of an extracellular agent [correction of catalyst] of carbon tetrachloride dehalogenation from Pseudomonas stutzeri strain KC as pyridine-2, 6-bis (thiocarboxylate). Biochem Biophys Res Commun 261: 562-566. 
Lehoux, D.E., Sanschagrin, F., and Levesque, R.C. (2000) Genomics of the 35-kb pvd locus and analysis of novel pvdlJK genes implicated in pyoverdine biosynthesis in Pseudomonas aeruginosa. FEMS Microbiol Lett 190: 141-146.

Lewis, T.A., Leach, L., Morales, S., Austin, P.R., Hartwell, H. J., Kaplan, B., et al. (2004) Physiological and molecular genetic evaluation of the dechlorination agent, pyridine2,6-bis(monothiocarboxylic acid) (PDTC) as a secondary siderophore of Pseudomonas. Environ Microbiol 6: 159-169.

Lin, P.-C., Youard, Z.A., and Reimmann, C. (2013) In vitrobinding of the natural siderophore enantiomers pyochelin and enantiopyochelin to their AraC-type regulators PchR in Pseudomonas. Biometals 26: 1067-1073.

Llamas, M.A., Imperi, F., Visca, P., and Lamont, I.L. (2014) Cell-surface signaling in Pseudomonas: stress responses, iron transport, and pathogenicity. FEMS Microbiol Rev 38: 569-597.

Llamas, M.A., Mooij, M.J., Sparrius, M., VandenbrouckeGrauls, C.M., Ratledge, C., and Bitter, W. (2008) Characterization of five novel Pseudomonas aeruginosa cellsurface signalling systems. Mol Microbiol 67: 458-472.

Llamas, M.A., Sparrius, M., Kloet, R., Jimenez, C.R., Vandenbroucke-Grauls, C., and Bitter, W. (2006) The heterologous siderophores ferrioxamine $\mathrm{B}$ and ferrichrome activate signaling pathways in Pseudomonas aeruginosa. J Bacteriol 188: 1882-1891.

Manley, S., Gillette, J.M., Patterson, G.H., Shroff, H., Hess, H.F., Betzig, E., and Lippincott-Schwartz, J. (2008) High-density mapping of single-molecule trajectories with photoactivated localization microscopy. Nat Methods 5 : 155-157.

Matthijs, S., Baysse, C., Koedam, N., Tehrani, K.A., Verheyden, L., Budzikiewicz, H., et al. (2004) The Pseudomonas siderophore quinolobactin is synthesized from xanthurenic acid, an intermediate of the kynurenine pathway. Mol Microbiol 52: 371-384.

Matthijs, S., Budzikiewicz, H., Schafer, M., Wathelet, B., and Cornelis, P. (2008) Ornicorrugatin, a new siderophore from Pseudomonas fluorescens AF76. Z Naturforsch $C$ 63: 8-12.

Matthijs, S., Laus, G., Meyer, J.M., Abbaspour-Tehrani, K., Schafer, M., Budzikiewicz, H., and Cornelis, P. (2009) Siderophore-mediated iron acquisition in the entomopathogenic bacterium Pseudomonas entomophila L48 and its close relative Pseudomonas putida KT2440. Biometals 22: 951-964.

Matthijs, S., Tehrani, K.A., Laus, G., Jackson, R.W., Cooper, R.M., and Cornelis, P. (2007) Thioquinolobactin, a Pseudomonas siderophore with antifungal and antiPythium activity. Environ Microbiol 9: 425-434.

McMorran, B.J., Kumara, H.M., Sullivan, K., and Lamont, I.L. (2001) Involvement of a transformylase enzyme in siderophore synthesis in Pseudomonas aeruginosa. Microbiology 147: 1517-1524.

Meneely, K.M., Barr, E.W., Bollinger, J.M., Jr., and Lamb, A. L. (2009) Kinetic mechanism of ornithine hydroxylase (PvdA) from Pseudomonas aeruginosa: substrate triggering of $\mathrm{O}_{2}$ addition but not flavin reduction. Biochemistry 48: $4371-4376$.
Meneely, K.M., Luo, Q., Dhar, P., and Lamb, A.L. (2013) Lysine221 is the general base residue of the isochorismate synthase from Pseudomonas aeruginosa $(\mathrm{Pch} A)$ in a reaction that is diffusion limited. Arch Biochem Biophys 538: 49-56.

Mercado-Blanco, J., van der Drift, K.M., Olsson, P.E., Thomas-Oates, J.E., van Loon, L.C., and Bakker, P.A. (2001) Analysis of the pmsCEAB gene cluster involved in biosynthesis of salicylic acid and the siderophore pseudomonine in the biocontrol strain Pseudomonas fluorescens WCS374. J Bacteriol 183: 1909-1920.

Merriman, T.R., Merriman, M.E., and Lamont, I.L. (1995) Nucleotide sequence of pvdD, a pyoverdine biosynthetic gene from Pseudomonas aeruginosa: PvdD has similarity to peptide synthetases. J Bacteriol 177: 252-258.

Meyer, J.M., Geoffroy, V.A., Baida, N., Gardan, L., Izard, D., Lemanceau, P., et al. (2002) Siderophore typing, a powerful tool for the identification of fluorescent and nonfluorescent pseudomonads. Appl Environ Microbiol 68: 2745-2753.

Meyer, J.M., Neely, A., Stintzi, A., Georges, C., and Holder, I.A. (1996) Pyoverdin is essential for virulence of Pseudomonas aeruginosa. Infect Immun 64: 518-523.

Meyer, J.M., Stintzi, A., De Vos, D., Cornelis, P., Tappe, R., Taraz, K., and Budzikiewicz, H. (1997) Use of siderophores to type pseudomonads: the three Pseudomonas aeruginosa pyoverdine systems. Microbiology 143: 35-43.

Michel, L., Bachelard, A., and Reimmann, C. (2007) Ferripyochelin uptake genes are involved in pyochelinmediated signalling in Pseudomonas aeruginosa. Microbiology 153: 1508-1518.

Michel, L., Gonzalez, N., Jagdeep, S., Nguyen-Ngoc, T., and Reimmann, C. (2005) PchR-box recognition by the AraCtype regulator PchR of $P$ seudomonas aeruginosa requires the siderophore pyochelin as an effector. Mol Microbiol 58: 495-509.

Minandri, F., Imperi, F., Frangipani, E., Bonchi, C., Visaggio, D., Facchini, M., et al. (2016) Role of iron uptake systems in Pseudomonas aeruginosa virulence and airway infection. Infect Immun 84: 2324-2335.

Mirleau, n., Delorme, n., Philippot, n., Meyer, n., Mazurier, n., and Lemanceau, n. (2000) Fitness in soil and rhizosphere of Pseudomonas fluorescens C7R12 compared with a C7R12 mutant affected in pyoverdine synthesis and uptake. FEMS Microbiol Ecol 34: 35-44.

Mislin, G.L.A., and Schalk, I.J. (2014) Siderophoredependent iron uptake systems as gates for antibiotic Trojan horse strategies against Pseudomonas aeruginosa. Metallomics 6: 408-420.

Moon, C.D., Zhang, X.-X., Matthijs, S., Schäfer, M., Budzikiewicz, H., and Rainey, P.B. (2008) Genomic, genetic and structural analysis of pyoverdine-mediated iron acquisition in the plant growth-promoting bacterium Pseudomonas fluorescens SBW25. BMC Microbiol 8: 7.

Mossialos, D., and Amoutzias, G.D. (2007) Siderophores in fluorescent pseudomonads: new trick from an old dog. Future Microbiol 2: 387-395.

Mossialos, D., Ochsner, U., Baysse, C., Chablain, P., Pirnay, J.P., Koedam, N., et al. (2002) Identification of new, conserved, non-ribosomal peptide synthetases from 
fluorescent pseudomonads involved in the biosynthesis of the siderophore pyoverdine. Mol Microbiol 45: 1673-1685.

Nadal-Jimenez, P., Koch, G., Reis, C.R., Muntendam, R., Raj, H., Jeronimus-Stratingh, C.M., et al. (2014) PvdP is a tyrosinase that drives maturation of the pyoverdine chromophore in Pseudomonas aeruginosa. J Bacteriol 196: 2681-2690.

Ochsner, U.A., Johnson, Z., Lamont, I.L., Cunliffe, H.E., and Vasil, M.L. (1996) Exotoxin A production in Pseudomonas aeruginosa requires the iron-regulated pvdS gene encoding an alternative sigma factor. Mol Microbiol 21: 1019-1028.

Ochsner, U.A., Vasil, A.I., and Vasil, M.L. (1995) Role of the ferric uptake regulator of Pseudomonas aeruginosa in the regulation of siderophores and exotoxin $A$ expression: purification and activity on iron-regulated promoters. J Bacteriol 177: 7194-7201.

Ockels, W., Römer, A., Budzikiewicz, H., Korth, H., and Pulverer, G. (1978) An Fe(II) complex of pyridine-2,6-di(monothiocarboxylic acid) - a novel bacterial metabolic product. Tetrahedron Lett 19: 3341-3342.

Owen, J.G., and Ackerley, D.F. (2011) Characterization of pyoverdine and achromobactin in Pseudomonas syringae pv. phaseolicola 1448a. BMC Microbiol 11: 218.

Özkaya, Ö., Balbontín, R., Gordo, I., and Xavier, K.B. (2018) Cheating on cheaters stabilizes cooperation in Pseudomonas aeruginosa. Curr Biol 28: 2070-2080.e6.

Patel, H.M., Tao, J., and Walsh, C.T. (2003) Epimerization of an L-cysteinyl to a D-cysteinyl residue during thiazoline ring formation in siderophore chain elongation by pyochelin synthetase from Pseudomonas aeruginosa. Biochemistry 42: 10514-10527.

Patel, H.M., and Walsh, C.T. (2001) In vitro reconstitution of the Pseudomonas aeruginosa nonribosomal peptide synthesis of pyochelin: characterization of backbone tailoring thiazoline reductase and $\mathrm{N}$-methyltransferase activities. Biochemistry 40: 9023-9031.

Paulsen, I.T., Press, C.M., Ravel, J., Kobayashi, D.Y., Myers, G.S.A., Mavrodi, D.V., et al. (2005) Complete genome sequence of the plant commensal Pseudomonas fluorescens Pf-5. Nat Biotechnol 23: 873-878.

Perraud, Q., Cantero, Paola, P., Roche, B., Gasser, V., Normant, V., et al. (2020) Phenotypic adaption of Pseudomonas aeruginosa by hacking siderophores produced by other microorganisms. Mol Cell Proteomics.

Petermann, S.R., Sherwood, J.S., and Logue, C.M. (2008) The Yersinia high pathogenicity Island is present in Salmonella enterica subspecies I isolated from turkeys. Microb Pathog 45: 110-114.

Poole, K., Neshat, S., and Heinrichs, D. (1991) Pyoverdinemediated iron transport in Pseudomonas aeruginosa: involvement of a high-molecular-mass outer membrane protein. FEMS Microbiol Lett 62: 1-5.

Poppe, J., Reichelt, J., and Blankenfeldt, W. (2018) Pseudomonas aeruginosa pyoverdine maturation enzyme PvdP has a noncanonical domain architecture and affords insight into a new subclass of tyrosinases. $J$ Biol Chem 293: 14926-14936.

Prince, R.W., Cox, C.D., and Vasil, M.L. (1993) Coordinate regulation of siderophore and exotoxin $A$ production: molecular cloning and sequencing of the Pseudomonas aeruginosa fur gene. J Bacteriol 175: 2589-2598.

Ravel, J., and Cornelis, P. (2003) Genomics of pyoverdinemediated iron uptake in pseudomonads. Trends Microbiol 11: 195-200.

Redly, G.A., and Poole, K. (2003) Pyoverdine-mediated regulation of FpvA synthesis in Pseudomonas aeruginosa: involvement of a probable extracytoplasmic-function sigma factor, Fpvl. J Bacteriol 185: 1261-1265.

Redly, G.A., and Poole, K. (2005) FpvIR control of fpvA ferric pyoverdine receptor gene expression in Pseudomonas aeruginosa: demonstration of an interaction between Fpvl and FpvR and identification of mutations in each compromising this interaction. $J$ Bacteriol 187: 5648-5657.

Reimmann, C., Patel, H.M., Serino, L., Barone, M., Walsh, C.T., and Haas, D. (2001) Essential PchGdependent reduction in pyochelin biosynthesis of Pseudomonas aeruginosa. J Bacteriol 183: 813-820.

Reimmann, C., Patel, H.M., Walsh, C.T., and Haas, D. (2004) PchC thioesterase optimizes nonribosomal biosynthesis of the peptide siderophore pyochelin in Pseudomonas aeruginosa. J Bacteriol 186: 6367-6373.

Reimmann, C., Serino, L., Beyeler, M., and Haas, D. (1998) Dihydroaeruginoic acid synthetase and pyochelin synthetase, products of the pchEF genes, are induced by extracellular pyochelin in Pseudomonas aeruginosa. Microbiology 144: 3135-3148.

Ringel, M.T., and Brüser, T. (2018) The biosynthesis of pyoverdines. Microb Cell 5: 424-437.

Ringel, M.T., Dräger, G., and Brüser, T. (2017) The periplasmic transaminase PtaA of Pseudomonas fluorescens converts the glutamic acid residue at the pyoverdine fluorophore to $\alpha$-ketoglutaric acid. $J$ Biol Chem 292: 18660-18671.

Ringel, M.T., Dräger, G., and Brüser, T. (2018) PvdO is required for the oxidation of dihydropyoverdine as the last step of fluorophore formation in Pseudomonas fluorescens. J Biol Chem 293: 2330-2341.

Ronnebaum, T.A., and Lamb, A.L. (2018) Nonribosomal peptides for iron acquisition: pyochelin biosynthesis as a case study. Curr Opin Struct Biol 53: 1-11.

Ronnebaum, T.A., McFarlane, J.S., Prisinzano, T.E., Booker, S.J., and Lamb, A.L. (2019) Stuffed Methyltransferase catalyzes the penultimate step of pyochelin biosynthesis. Biochemistry 58: 665-678.

Ruangviriyachai, C., Fernández, D.U., Fuchs, R., Meyer, J. M., and Budzikiewicz, H. (2001) A new pyoverdin from Pseudomonas aeruginosa R'. Z Naturforsch C 56: 933-938.

Schalk, I.J. (2018) Siderophore-antibiotic conjugates: exploiting iron uptake to deliver drugs into bacteria. Clin Microbiol Infect 24: 801-802.

Schalk, I.J., and Guillon, L. (2013) Pyoverdine biosynthesis and secretion in Pseudomonas aeruginosa: implications for metal homeostasis. Environ Microbiol 15: 1661-1673.

Schalk, I.J., and Mislin, G.L.A. (2017) Bacterial iron uptake pathways: gates for the import of bactericide compounds. $J$ Med Chem 60: 4573-4576.

Schalk, I.J., Mislin, G.L.A., and Brillet, K. (2012) Structure, function and binding selectivity and stereoselectivity of 
siderophore-iron outer membrane transporters. Curr Top Membr 69: 37-66.

Schmelz, S., Kadi, N., McMahon, S.A., Song, L., OvesCostales, D., Oke, M., et al. (2009) AcsD catalyzes enantioselective citrate desymmetrization in siderophore biosynthesis. Nat Chem Biol 5: 174-182.

Schmitt, D.L., and An, S. (2017) Spatial organization of metabolic enzyme complexes in cells. Biochemistry 56: 3184-3196.

Sepúlveda-Torre, L., Huang, A., Kim, H., and Criddle, C.S. (2002) Analysis of regulatory elements and genes required for carbon tetrachloride degradation in Pseudomonas stutzeri strain KC. J Mol Microbiol Biotechnol 4: 151-161.

Serino, L., Reimmann, C., Visca, P., Beyeler, M., Chiesa, V. D., and Haas, D. (1997) Biosynthesis of pyochelin and dihydroaeruginoic acid requires the iron-regulated pchDCBA operon in Pseudomonas aeruginosa. J Bacteriol 179: 248-257.

Smith, E.E., Sims, E.H., Spencer, D.H., Kaul, R., and Olson, M.V. (2005) Evidence for diversifying selection at the pyoverdine locus of Pseudomonas aeruginosa. $J$ Bacteriol 187: 2138-2147.

Spencer, D.H., Kas, A., Smith, E.E., Raymond, C.K., Sims, E.H., Hastings, M., et al. (2003) Whole-genome sequence variation among multiple isolates of Pseudomonas aeruginosa. J Bacteriol 185: 1316-1325.

Spencer, M.R., Beare, P.A., and Lamont, I.L. (2008) Role of cell surface signaling in proteolysis of an alternative sigma factor in Pseudomonas aeruginosa. J Bacteriol 190: 4865-4869.

Stilwell, P., Lowe, C., and Buckling, A. (2018) The effect of cheats on siderophore diversity in Pseudomonas aeruginosa. J Evol Biol 31: 1330-1339.

Süssmuth, R.D., and Mainz, A. (2017) Nonribosomal peptide synthesis-principles and prospects. Angew Chem Int Ed Engl 56: 3770-3821.

Taguchi, F., Suzuki, T., Inagaki, Y., Toyoda, K., Shiraishi, T., and Ichinose, Y. (2010) The siderophore pyoverdine of Pseudomonas syringae pv. tabaci 6605 is an intrinsic virulence factor in host tobacco infection. J Bacteriol 192: 117-126.

Tseng, C.F., Burger, A., Mislin, G.L.A., Schalk, I.J., Yu, S.S.F., Chan, S.I., and Abdallah, M.A. (2006) Bacterial siderophores: the solution stoichiometry and coordination of the $\mathrm{Fe}(\mathrm{III})$ complexes of pyochelin and related compounds. J Biol Inorg Chem 11: 419-432.

Vandenende, C.S., Vlasschaert, M., and Seah, S.Y. (2004) Functional characterization of an aminotransferase required for pyoverdine siderophore biosynthesis in Pseudomonas aeruginosa PA01. J Bacteriol 186: 5596-5602.

Vasil, M.L., Ochsner, U.A., Johnson, Z., Colmer, J.A., and Hamood, A,N. (1998) The fur-regulated gene encoding the alternative sigma factor PvdS is required for iron-dependent expression of the LysR-type regulator ptxR in Pseudomonas aeruginosa. J Bacteriol 180: 6784-6788.

Visca, P. (2004). In Iron Regulation and Siderophore Signalling in Virulence by Pseudomonas aeruginosa. Pseudomonas, Vol. 2, Ramos, J.-L. (ed). New York: Kluver Academic/Plenum Publishers, pp. 69-123.

Visca, P., Ciervo, A., and Orsi, N. (1994) Cloning and nucleotide sequence of the pvdA gene encoding the pyoverdin biosynthetic enzyme L-ornithine N5-oxygenase in Pseudomonas aeruginosa. J Bacteriol 176: 1128-1140.

Visca, P., Imperi, F., and Lamont, I.L. (2007) Pyoverdine siderophores: from biogenesis to biosignificance. Trends Microbiol 15: 22-30.

Wilderman, P.J., Vasil, A.l., Johnson, Z., Wilson, M.J., Cunliffe, H.E., Lamont, I.L., and Vasil, M.L. (2001) Characterization of an endoprotease (PrpL) encoded by a PvdSregulated gene in Pseudomonas aeruginosa. Infect Immun 69: 5385-5394.

Wilson, M.J., and Lamont, I.L. (2000) Characterization of an ECF sigma factor protein from Pseudomonas aeruginosa. Biochem Biophys Res Commun 273: 578-583.

Wilson, M.J., McMorran, B.J., and Lamont, I.L. (2001) Analysis of promoters recognized by PvdS, an extracytoplasmic-function sigma factor protein from Pseudomonas aeruginosa. J Bacteriol 183: 2151-2155.

Yang, L., Nilsson, M., Gjermansen, M., Givskov, M., and Tolker-Nielsen, T. (2009) Pyoverdine and PQS mediated subpopulation interactions involved in Pseudomonas aeruginosa biofilm formation. Mol Microbiol 74: 1380-1392.

Yeterian, E., Martin, L.W., Guillon, L., Journet, L., Lamont, I. L., and Schalk, I.J. (2010) Synthesis of the siderophore pyoverdine in Pseudomonas aeruginosa involves a periplasmic maturation. Amino Acids 38: 1447-1459.

Youard, Z.A., Mislin, G.L., Majcherczyk, P.A., Schalk, I.J., and Reimmann, C. (2007) Pseudomonas fluorescens $\mathrm{CHAO}$ produces enantio-pyochelin, the optical antipode of the Pseudomonas aeruginosa siderophore pyochelin. J Biol Chem 282: 35546-35553.

Youard, Z.A., Wenner, N., and Reimmann, C. (2011) Iron acquisition with the natural siderophore enantiomers pyochelin and enantio-pyochelin in Pseudomonas species. Biometals 24: 513-522.

Yuan, Z., Gao, F., Bai, G., Xia, H., Gu, L., and Xu, S. (2017) Crystal structure of PvdO from Pseudomonas aeruginosa. Biochem Biophys Res Commun 484: 195-201.

Zaborin, A., Romanowski, K., Gerdes, S., Holbrook, C., Lepine, F., Long, J., et al. (2009) Red death in Caenorhabditis elegans caused by Pseudomonas aeruginosa PAO1. Proc Natl Acad Sci U S A 106: 6327-6332. 